\title{
Bathymetry and productivity of the southern Great Basin seaway, Nevada, USA: An evaluation of isotope and trace element chemistry in mid-Carboniferous and modern brachiopods
}

\author{
Uwe Brand $^{\mathrm{a}, \star}$, Gary D. Webster ${ }^{\mathrm{b}}$, Karem Azmy ${ }^{\mathrm{c}}$, A. Logan ${ }^{\mathrm{d}}$ \\ a Department of Earth Sciences, Brock University, St. Catharines, Ontario, Canada L2S 3A1 \\ b Department of Geology, Washington State University, Pullman, WA 99164-2812, USA \\ c Department of Earth Sciences, Memorial University of Newfoundland, St. John's, Newfoundland, Canada A1B 3X5 \\ ${ }^{\mathrm{d}}$ Centre for Coastal Studies and Aquaculture, University of New Brunswick, Saint John, New Brunswick, Canada E2L 4L5
}

Accepted 15 February 2007

\begin{abstract}
The stable isotope and trace element chemistry of brachiopods from stratigraphically, paleontologically, and geochemically three coeval intervals about the mid-Carboniferous boundary in the Bird Spring Formation were evaluated for their potential of serving as proxies of bathymetry and productivity of the southern Great Basin seaway, an eastern arm of the Panthalassa Ocean. Oxygen isotopes delineate both spatial and temporal differences in values of brachiopods from the three coeval mid-Carboniferous sections. Based on pristine brachiopod $\delta^{18} \mathrm{O}$ values and supported by paleoecological information, water depth increased from Apex to Kane Springs Wash East to Arrow Canyon. In addition, there is also an increase in values from the latest Mississippian to the earliest Pennsylvanian suggesting a water temperature (cooling), a water depth (increase), and/or change in both of the habitat of the penecontemporaneous brachiopods.

Analogous to values and trends observed in modern brachiopods, the Fe/Mn ratio of fossil counterparts may be a potential proxy of seawater productivity related to the micronutrient iron. Overall, the high ratios of $\mathrm{Fe} / \mathrm{Mn}$ suggest highly productive waters for the southern Great Basin seaway, with somewhat reduced productivity during the earliest Pennsylvanian. In contrast, the carbon isotope values of the coeval material are relatively invariant with respect to productivity; trends similar to observations on modern carbonate allochems. Based on habitat and paleogeography, the Antler Orogenic Highlands west of the foreland basin are considered a potential source for the micronutrient iron enrichment of the carbonate platform shelf-edge environment. It is further postulated that upwelling currents, in part, which weakened from the latest Mississippian through to the earliest Pennsylvanian, may have transported the micronutrient iron onto the shelf/basin environments of the Bird Spring Formation of the southern Great Basin.
\end{abstract}

(c) 2007 Elsevier B.V. All rights reserved.

Keywords: Brachiopod biogeochemistry; Mid-Carboniferous; Modern; Southern Great Basin seaway; Bathymetry; Productivity; Upwelling

\footnotetext{
* Corresponding author. Tel.: +1 905688 5550x3529; fax: +1 905 6829020.

E-mail address: uwe.brand@brocku.ca (U. Brand).
}

\section{Introduction}

Low-Mg calcite articulated brachiopods, if preserved in their original shell microstructure, mineralogy and geochemistry, should be powerful proxies of ambient 
seawater quality and chemistry (e.g., Popp et al., 1986; Veizer et al., 1986; Adlis et al., 1988; Bates and Brand, 1991; Marshall, 1992; Grossman, 1994; Veizer et al., 1999; Mii et al., 1999; Brand, 2004; Lee et al., 2004). After detailed evaluation by all possible parameters (such as microstructures, cathodoluminescence, trace element, and stable isotope chemistry) coupled with a horizon-by-horizon analysis strategy, one should be able to identify brachiopod material that, in all probability, represents shells in pristine conditions and thus reflects original seawater chemistry (e.g., Brand and Veizer, 1980; Brand, 1991; Grossman, 1994; Brand, 2004). This capability to confidently discern 'original proxy material' through a battery of detailed tests is complemented by the increasing availability of biogeochemical information from modern brachiopods, which provides important baseline oceanographic information for comparative evaluations of proxy results from fossil brachiopods (e.g., Lowenstam, 1961; Morrison and Brand, 1986; Carpenter and Lohmann, 1995; Buening and Spero, 1996; James et al., 1997; Auclair et al., 2003; Brand et al., 2003; Lee et al., 2004; Parkinson et al., 2005). Although these studies provide important baseline information, they caution the reader that much is still to be learned about the chemical distribution in brachiopod shells and its ecological interpretation and connection to ambient seawater chemistry. Thus, more incisive studies both on modern and fossil brachiopods are needed to resolve some of these on-going issues for this most important group of organisms so that their full potential as original seawater proxies may be realized.

Few studies have attempted to resolve the issue of identifying bathymetry from the geochemical results of fossil brachiopods (e.g., Adlis et al., 1988; Bates and Brand, 1991; Brenchley et al., 1994; Azmy et al., 2006). However few, the studies on modern brachiopods may explicitly demonstrate a relationship between water depth (temperature) and oxygen isotopes (e.g., Lowenstam, 1961; James et al., 1997; Brand et al., 2003). In general, it is assumed that Paleozoic brachiopods lived in seas with water depths of less than $200 \mathrm{~m}$ (Tasch, 1980), because many occur in association with reefal systems indicating shallow-water regimes. As such, comparison of brachiopod faunas from various localities is usually undertaken on assemblages from similar latitudes but with little consideration of differences in and impacts by water depth (temperature) and other ambient environmental parameters such as salinity (evaporation/dilution)

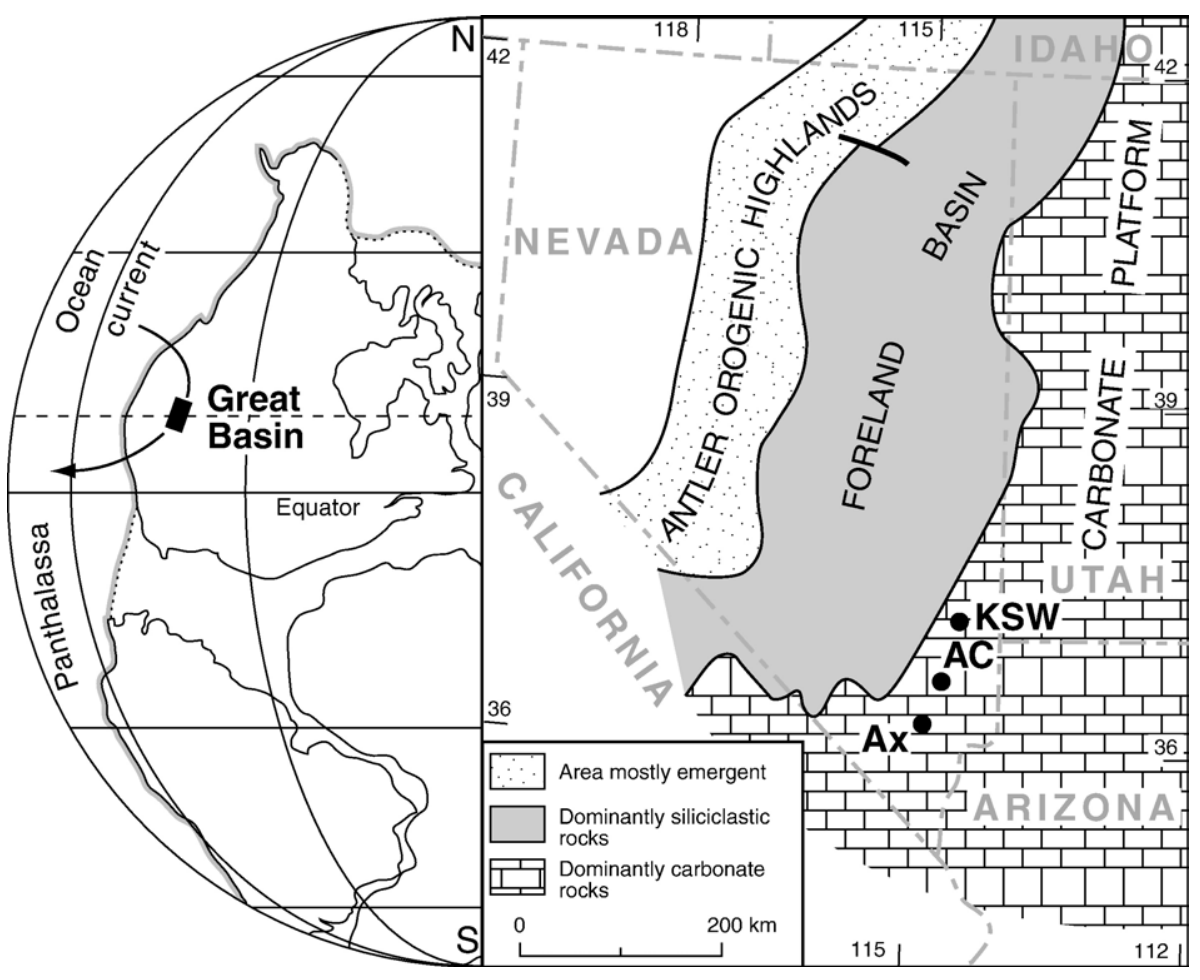

Fig. 1. Paleogeographic setting of the Great Basin in North America during the mid-Carboniferous (modified from Richards et al. (1994)). Detailed paleogeography of the southern seaway of the Great Basin with the location of three sampling sites at Arrow Canyon (AC), Apex (Ax) and Kane Springs Wash East (KSW) as observed today. 


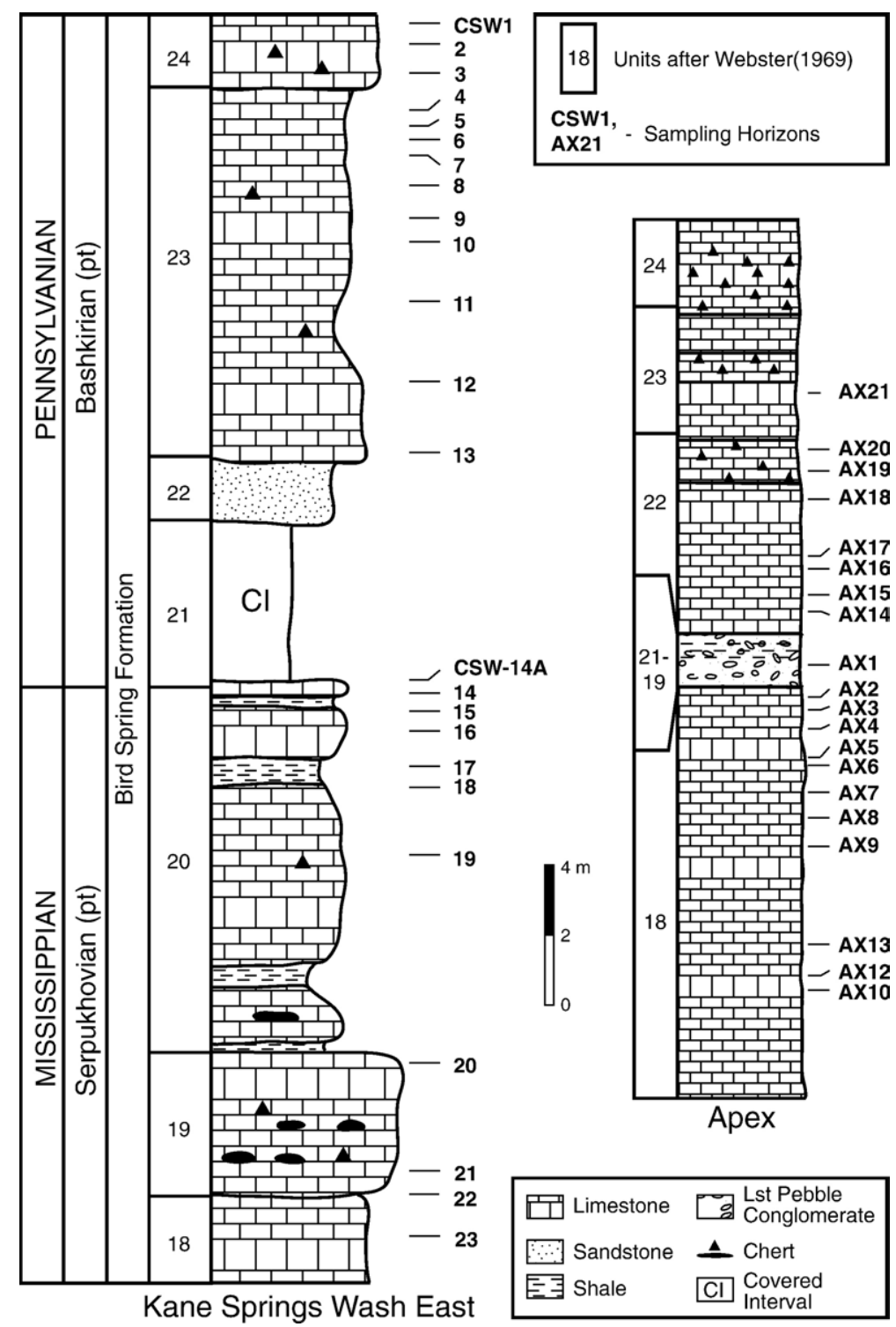

Fig. 2. Stratigraphic sequences of the Bird Spring Formation spanning the mid-Carboniferous boundary outcropping at Kane Springs Wash East and Apex, Nevada. The position of the boundary is based on the first appearance of the conodont 'noduliferous', and the unit descriptions and numbers are from Webster (1969). The CSW and AX numbers represent sample horizons collected for various allochems used in this study (Appendix).

on isotopic values (cf. Brand et al., 2003). Furthermore, bathymetric interpretations of fossil brachiopods rely on paleoecologic, faunal associations and/or sedimentologic indicators in deciphering their depth habitat, which may be lacking for some sites or difficult to discern from the available information and/or reconcile with the isotopic information (e.g., Azmy et al., 2006). The importance and impacts of these parameters were addressed by some authors in their studies and evaluation of fossil brachiopod chemistry but many issues remain unresolved or unsatisfactorily explained by the results (e.g., Bates and Brand, 1991; Grossman,
1994; Azmy et al., 2006). In contrast, the influence of seawater productivity on brachiopod abundance and distribution is essentially unstudied, and its application to studies of fossil and paleo-ocean chemistry remains unexplored. Complementary studies on marine phytoplankton give us a clear insight of the impact of macroand micronutrients on population dynamics, individual's sizes and their oceanic distribution (e.g., Broecker and Peng, 1982; Moore et al., 2002; Bruland et al., 2005). These and other studies demonstrated that the micronutrient iron plays a key role in limiting phytoplankton growth rates and the structuring of plankton 
communities (e.g., Martin et al., 1989; Takeda, 1998; Boyd and Harrison, 1999; others cited in Moore et al., 2002). Several studies documented considerable variability of $\mathrm{Fe} / \mathrm{C}$ ratios in phytoplankton relative to $\mathrm{Fe}$ availability (e.g., Sunda et al., 1991; Sunda, 1997). Despite this progress about macro- and micro-nutrients in surface waters of the oceans, there is still a lack of information about iron cycling, rates, and controls of the oceanic iron cycle (e.g., Price et al., 1994; Johnson et al., 1997). The fundamental information from these studies and those of the element Fe in modern brachiopod shells will be used to infer productivity regimes and controls for various near-shore marine settings.

The primary objective of this study is to assemble well-preserved brachiopod material from contemporaneous intervals at three localities of the southern Great Basin seaway that represent different water depths during the latest Mississippian-earliest Pennsylvanian (Fig. 1). This will be followed by a detailed evaluation of their geochemical compositions (especially oxygen isotopes) within the context of the inferred water depth differential. An attempt will be made to decipher the paleoproductivity of the southern Great Basin seaway by Fe the trace element proxy derived from the pristine brachiopods. This combination of water depth/productivity results may have new and important applications in resolving oceanographic issues of Paleozoic oceans and seas and stimulate more research in this potentially promising area.

\section{General geology}

Brachiopods were collected from numerous horizons (wherever present in sufficient size and numbers for biogeochemical evaluation) spanning the mid-Carboniferous boundary in the Bird Spring Formation at Arrow Canyon (supplementing the material of Brand and Brenckle, 2001), Apex, and Kane Springs Wash East in the Arrow Canyon and Delamar Ranges. From south to north, Apex to Arrow Canyon to Kane Springs Wash East, the individual localities are about equidistantly spaced ( 50 km; Fig. 1; Webster, 1969). The succession at Arrow Canyon was ratified as the GSSP for the mid-Carboniferous boundary by the IUGS in 1996 (Lane et al., 1999; Brand and Brenckle, 2001), whereas the other sections of the Bird Spring Formation were part of the regional mapping exercise in search of a suitable boundary section (e.g., Webster and Langenheim, 1979). The section at Apex is on the east limb of a gently dipping syncline in the southern end of the Arrow Canyon Range, Nevada. At this locality, the Bird Spring Formation consists mostly of fossiliferous, thin- to medium-bedded wacke- to packstones with some minor chert, and a small interval containing a limestone pebble conglomerate, quartzite and sandy shale numbered as beds 19 to 21 . Bed '19' was designated as the Mississippian-Pennsylvanian boundary horizon based on the first appearance of the conodont Rhachistognathus primus (Fig. 2; Webster, 1969). The section at Arrow Canyon has been described in geochemical detail by Brand and Brenckle (2001) with additional lithological descriptions supplied by many others (e.g., Langenheim and Langenheim, 1965; Heath et al., 1967; Webster, 1969; Lane et al., 1999). The GSSP boundary was set at the first appearance of Declinognathodus noduliferous s.l. at 82.90-83.05 $\mathrm{m}$ above the top of the Battleship Wash Formation in the lower Bird Spring Formation (Lane et al., 1999; Brand and Brenckle, 2001). The Kane Springs Wash East section is similar in lithology to the succession described at Arrow Canyon. The mostly carbonate sequence is punctuated by some minor shale and sandstone horizons (Fig. 2). At this locality, the Mississippian-Pennsylvanian boundary is placed within bed \# 21 (lowermost layer) identified as calcareous sandstone by Webster (1969). The sampling horizons are clearly labeled on the sections and cover beds 18 through 23 at Apex, and beds 18 through 24 at Kane Springs Wash East (Webster, 1969; Fig. 2).

Although the three sections are nearly in a northsouth alignment at present day, the Arrow Canyon and Kane Springs Wash East sections were moved eastward to be positioned northeast of the Apex section as a result of thrusting in the southern Great Basin and translational movement along the Las Vegas shear zone (Bowyer et al., 1958; Longwell, 1960). All three sections were deposited in the carbonate-dominated shelf of the Mississippian-Pennsylvanian foreland basin that was deepening to the west and north of the Las VegasWasatch line (Longwell et al., 1965; Rich, 1977; Larson and Langenheim, 1979). Thus, the Apex section sediments were originally deposited in a much shallower setting than those at the Arrow Canyon locality. Furthermore, Kane Springs Wash East section sediments were deposited in a slightly shallower setting than those at Arrow Canyon.

\section{Paleoecology}

Limestones of the lower part of the Bird Spring Formation (Unit \#2, Webster, 1969) are generally fossiliferous, fine- to medium-grained wacke- to packstones representing moderate- to high-energy environments. Webster (1969) divided Unit \#2 into a 

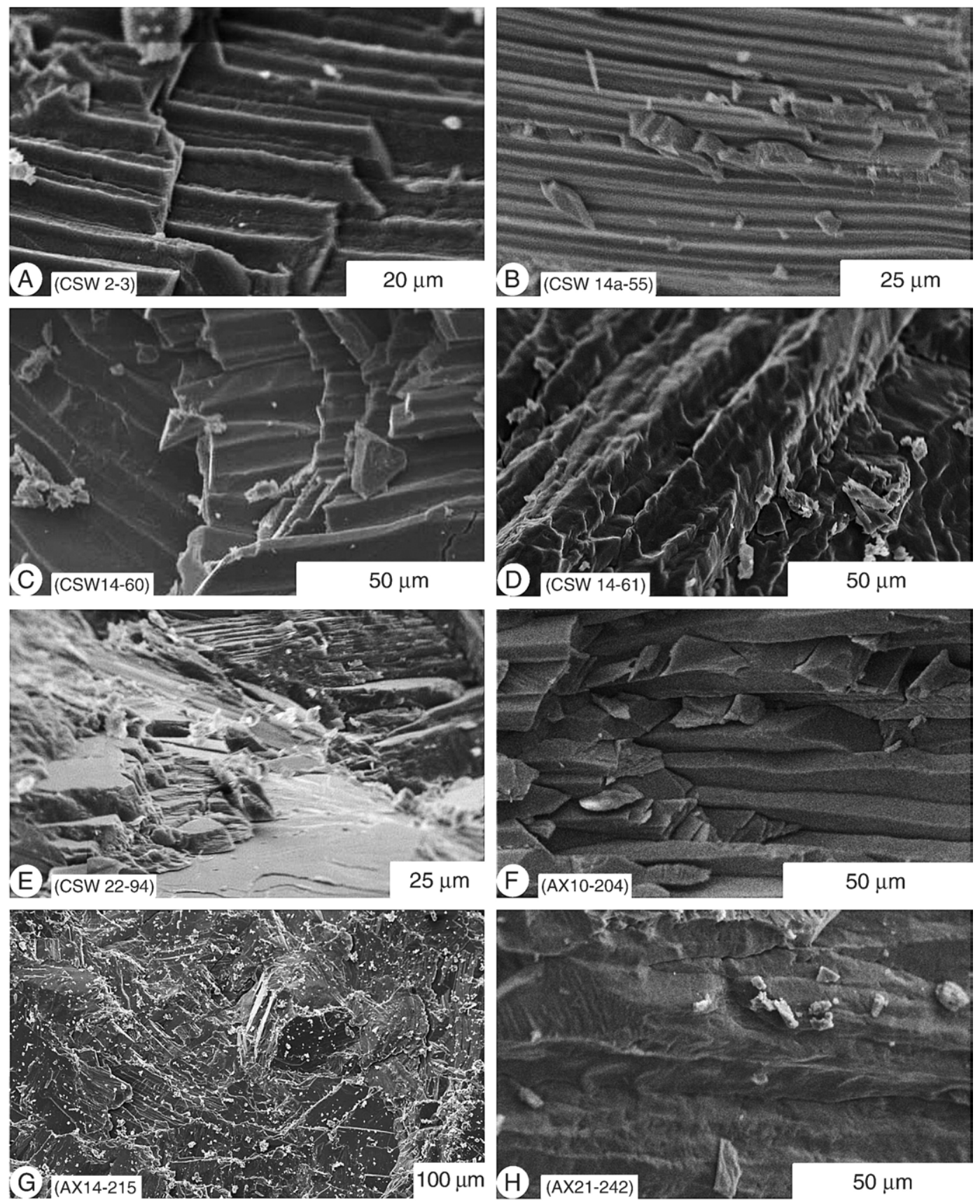

Fig. 3. Microstructures in brachiopods from the Bird Spring Formation at Apex (AX) and Kane Springs Wash East (CSW). (A) surface and crosssectional views of the well-preserved secondary layer fibers in specimen CSW2-3. (B) well-preserved secondary layer fibers in brachiopod sample CSW14a-55. (C) an oblique view of pristine fibers of the secondary layer in brachiopod specimen CSW14-60. (D) fibers of the secondary layer in specimen CSW14-61 which show extensive dissolution and rounding reflecting early stages of diagenetic alteration. (E) remnants of fibers (upper right corner) within coarse calcite indicating extensive diagenetic alteration and replacement of the secondary fibers (CSW22-94). (F) well-preserved fibers in shell layer of specimen AX10-204. (G) complete coarse calcite replacement of fibers in specimen AX14-215. (H) well-preserved fibers in specimen AX21-242 from the Bird Spring Formation at Apex.

southern and northern facies. The southern facies (Apex section, $183 \mathrm{ft}$ thick [55.8 m]) contains fewer arenaceous beds and most carbonates are fine to medium-grained wacke- and packstones containing a diverse fauna, including thin-shelled, delicate, spinose brachiopods often preserved in life position (Fig. 2). The northern 

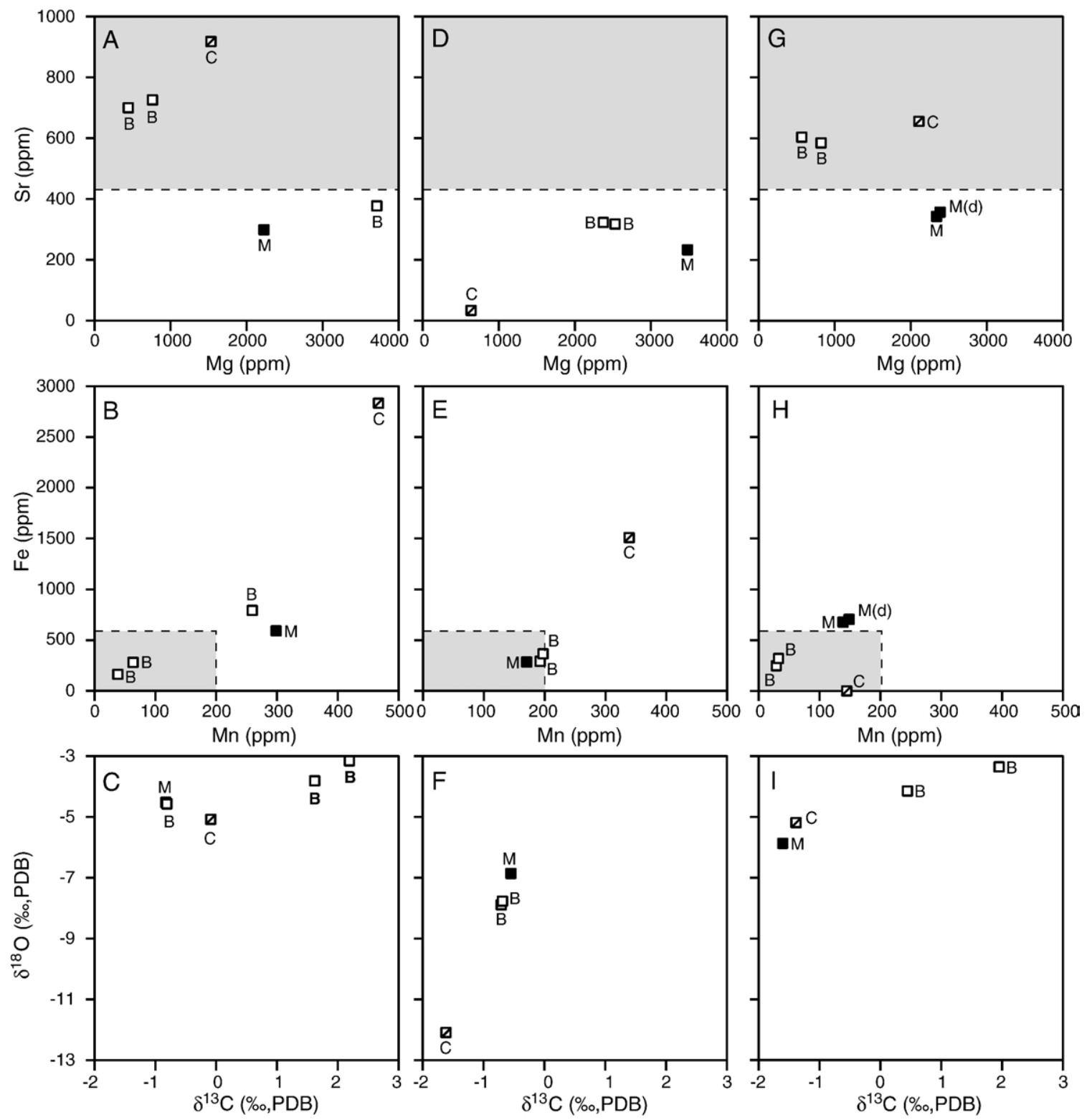

Fig. 4. Diagenetic trends in chemistry of brachiopods [B], matrix [M] and cement [C] sample sets from select horizons of the Bird Spring Formation at Kane Springs Wash East (A-C: CSW14a, and D-F: CSW23) and at Apex (G-I: AX2). The shaded areas represent ranges/limits of chemical concentrations of preserved material (cf. Denison et al., 1994; Veizer et al., 1999).

facies (Kane Springs Wash East, $543 \mathrm{ft}$ thick [165.5 m]) contains more arenaceous sediments, but the carbonates are predominantly wacke- to packstones with a diverse fauna with many of the same taxa preserved in a similar manner as in the southern facies (Fig. 2). Arrow Canyon, where Unit \#2 is $362 \mathrm{ft}$ thick [110.3 m], represents an interfingering of the southern and northern facies (Lane et al., 1999). Overall the sedimentary data, fossil occurrences, and preservation suggest moderately rapid deposition in a shallow-water, well-aerated environment at all three localities with greatest water depth at Arrow Canyon and shallowest at Apex (Webster, 1969).

\section{Methodology}

A total of 186 (122 brachiopods, 55 matrix, 9 cements) samples were analyzed for trace elements and isotopes 


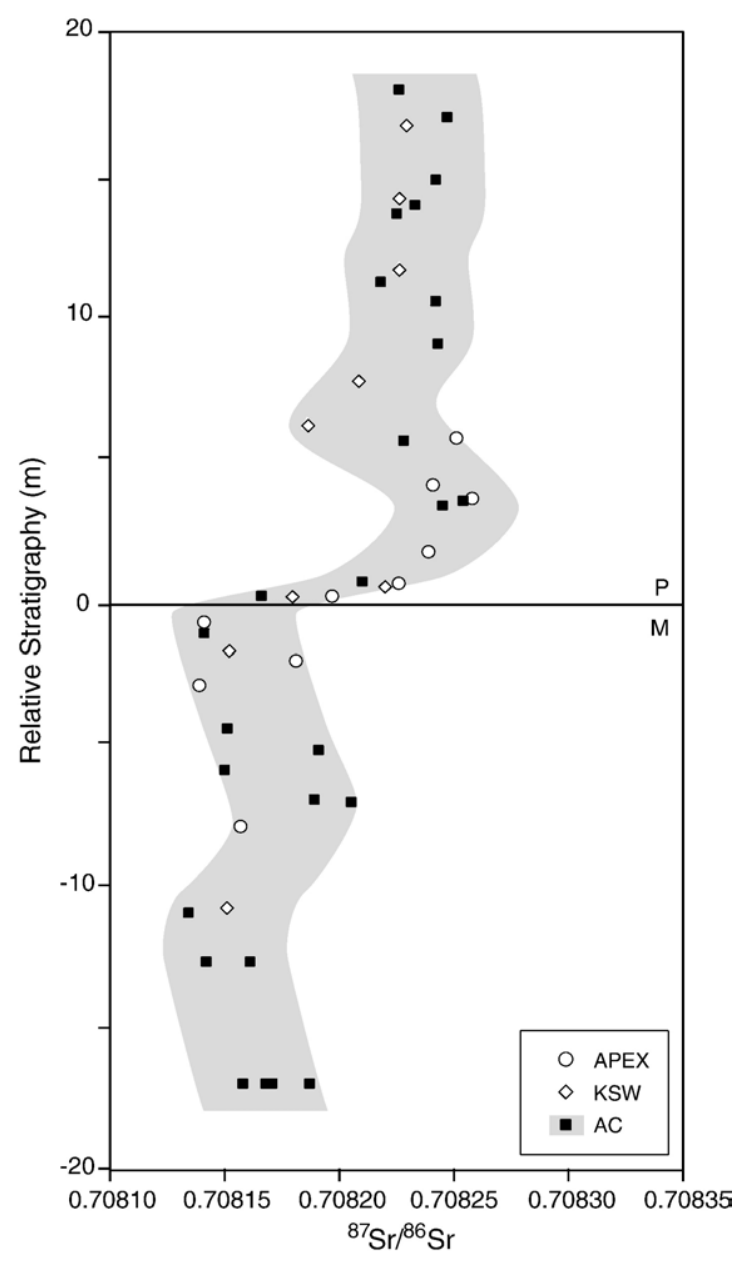

Fig. 5. Strontium isotope trend based on pristine brachiopods from the mid-Carboniferous Bird Spring Formation (GSSP; Lane et al., 1999, Brand and Brenckle, 2001) at Arrow Canyon (AC). The shaded envelope represents the 'normal' range of seawater variation based on modern shallow-water brachiopod data (Brand et al., 2003). The strontium isotope results of well-preserved brachiopods from the Bird Spring Formation at Kane Springs Wash East and Apex are superimposed on the AC trend. The ' 0 ' marker represents the Mississippian-Pennsylvanian boundary (M, P), and placement of samples was according to stratigraphic measurements (Fig. 2; Appendix).

from the Bird Spring Formation at Arrow Canyon, Apex, and Kane Springs Wash East (Fig. 1; Appendix). Brachiopods were extracted from the surrounding rock, cleaned by physical and chemical means (e.g., leached with $10 \% \mathrm{HCl}$ until specimens were deemed clean including free of iron/manganese oxide/hydroxide coatings), rinsed with distilled water, and left to air-dry. For surrounding rocks (matrix), all extraneous biogenic fragments and weathered material were removed. All brachiopods, mostly as fragments, were examined visually and most by scanning electron microscope for physical preservation of microstructural layers and of individual fibers. Up to $100 \mathrm{mg}$ of powder (brachiopods, matrix, cement) of each was digested in $5 \%(\mathrm{v} / \mathrm{v}) \mathrm{HNO}_{3}$ for 70-80 min. This weak acid digestion and time-limited process minimizes the leaching of elements such as $\mathrm{Fe}$ and $\mathrm{Mn}$ from any adhering non-carbonate fraction, if any, not removed during the cleaning process (cf. Brand and Veizer, 1980). After filtration, the non-carbonate portion (IR - insoluble residue) was determined gravimetrically by ashing the filtrate. All glass and plasticware was cleaned with aqua regia. N.B.S. (now NIST) and U.S.G.S. SRMs (standard reference materials), 634, 636, 19-IAEA, 987, EN-1, sample duplicates and blanks, were analysed to satisfy general quality assurance/quality control requirements (Brand and Veizer, 1980; Brand and Brenckle, 2001). The $\mathrm{Ca}, \mathrm{Mg}, \mathrm{Sr}, \mathrm{Na}, \mathrm{Fe}$ and $\mathrm{Mn}$

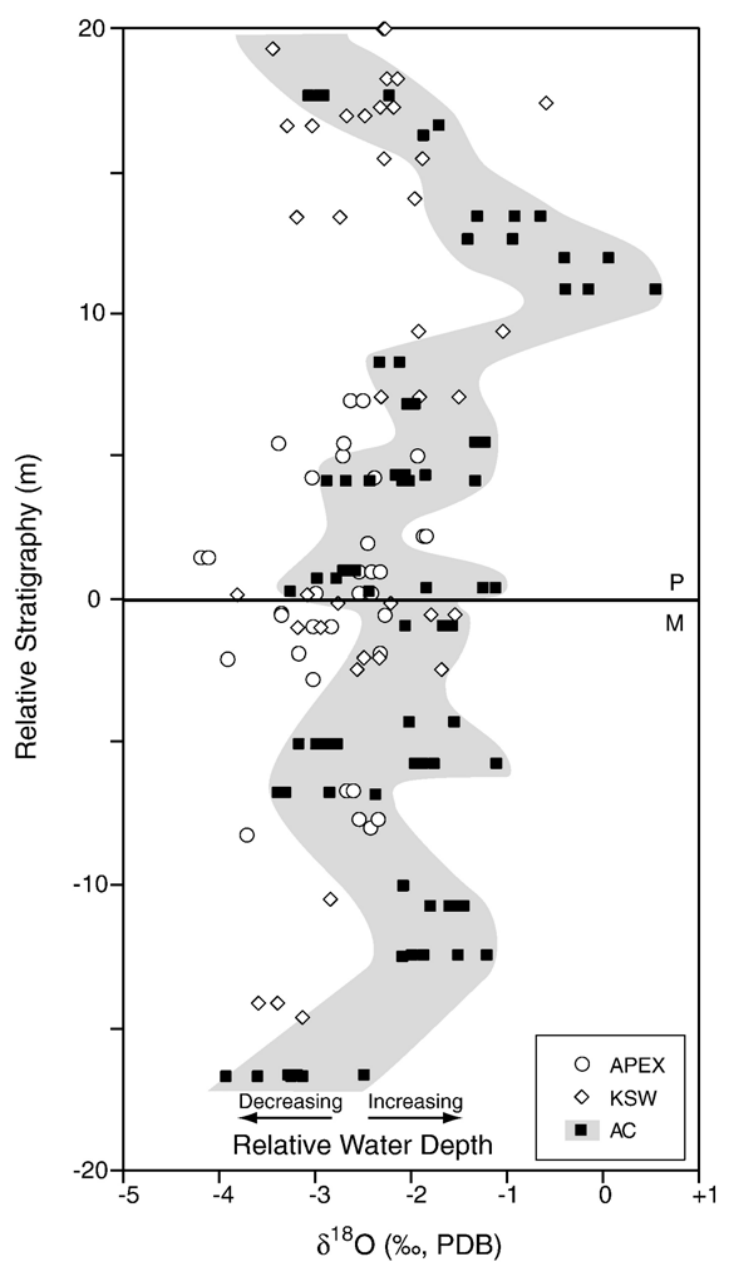

Fig. 6. Oxygen isotope trend of pristine brachiopod material from the Bird Spring Formation covering about $( \pm 20 \mathrm{~m})$ of the midCarboniferous boundary at Apex, Kane Springs Wash East and Arrow Canyon, Great Basin, Nevada. The boundary placement is based on Brand and Brenckle (2001), and shaded trend highlights the variation observed in the results from Arrow Canyon. 
Table 1

Statistical analysis (one-way ANOVA) of oxygen isotopes of preserved brachiopods from the Bird Spring Formation about the mid-Carboniferous boundary at Apex, Kane Springs Wash East and Arrow Canyon, Great Basin, Nevada

\begin{tabular}{|c|c|c|c|c|c|}
\hline Parameter & Apex & Kane Springs & $\begin{array}{l}\text { Arrow } \\
\text { Canyon }\end{array}$ & $\mathrm{p}$ & $\Delta^{18} \mathrm{O}$ \\
\hline \multicolumn{6}{|c|}{ Pennsylvanian } \\
\hline$\delta^{18} \mathrm{O}(\% \circ)$ & $\begin{array}{l}-2.68(19) \\
-2.68(19)\end{array}$ & $\begin{array}{l}-2.29(23) \\
-2.29(23)\end{array}$ & $\begin{array}{l}-1.84(43) \\
-1.84(43)\end{array}$ & $\begin{array}{l}0.073 \\
0.043 \\
0.001\end{array}$ & $\begin{array}{l}0.39 \\
0.45 \\
0.84\end{array}$ \\
\hline \multicolumn{6}{|c|}{ ıvıIssıssippıalı } \\
\hline$\delta^{18} \mathrm{O}(\% \circ)$ & $\begin{array}{l}-3.09(17) \\
-3.09(17)\end{array}$ & $\begin{array}{l}-2.60(14) \\
-2.60(14)\end{array}$ & $\begin{array}{l}-2.30(40) \\
-2.30(40)\end{array}$ & $\begin{array}{l}0.058 \\
0.200 \\
0.001\end{array}$ & $\begin{array}{l}0.49 \\
0.30 \\
0.79\end{array}$ \\
\hline $\mathrm{P}^{18} \mathrm{O}$ & $\begin{array}{l}0.079 \\
0.41\end{array}$ & $\begin{array}{l}0.187 \\
0.31\end{array}$ & $\begin{array}{l}0.016 \\
0.46\end{array}$ & & \\
\hline
\end{tabular}

Significance is at the $95 \%$ confidence level (pb0.050), $\Delta^{18} \mathrm{O}$ is the difference between mean values of pairs, $(\mathrm{N})=$ number of data.

elemental analyses were determined on a Varian 400P atomic absorption spectrophotometer at Brock University with an overall precision and accuracy better than 2.5 and $6.5 \%$, respectively for all elements (cf. Brand and Veizer, 1980).

A subset of samples was further analyzed for carbon and oxygen isotopes at the Universities of Basel and Ottawa (Appendix). Carbon and oxygen isotope results were analysed at a temperature of $25^{\circ} \mathrm{C}$ or corrected to a temperature of $25{ }^{\circ} \mathrm{C}$ and then are reported in the standard delta permil notation relative to PDB. The isotope laboratories claim precisions and accuracies that are better than 0.05 and $0.04 \%$, respectively relative to NBS 19-IAEA (cf. Brand and Brenckle, 2001).

A further subset of brachiopods from all three localities was analysed for strontium isotope ratios (Appendix). For these analyses about $1 \mathrm{mg}$ of select unaltered brachiopod samples were digested in $2.5 \mathrm{~N}$ suprapure $\mathrm{HCl}$ for about $24 \mathrm{~h}$ at room temperature. This was followed by separation with $4.5 \mathrm{~mL}$ of AGW 50X8 (Biorad) cation exchange resin in quartz glass columns to obtain purified Sr. Samples were analyzed on a Finnigan MAT 262 5-collector solid source mass spectrometer with single Ta filament (cf. Brand, 1991). Loading blank was below 5 pg, column blank was less than $1 \mathrm{ng}$, and reagent blank was below $0.01 \mathrm{ppb}$. The mean of 71 analyses of NBS 987 is $0.710238 \pm 0.000008$ $(2 \sigma)$, and the mean for six analyses of the SRM in this run is $0.710235 \pm 0.000005(2 \sigma)$, and the mean of 20 analyses of ocean water off Norway and France is 0.709149 $\pm 0.000020(2 \sigma)$. All strontium isotope data were normalized to a value of 0.710240 for NBS 987. Precision of duplicate analyses was better than 0.000007 (cf. Brand, 1991). All results are presented in the Appendix.

\section{Diagenetic evaluation}

The use of any chemistry of fossils and/or matrix necessitates the critical evaluation of the results to assess any impact and degree of diagenetic alteration. Once this is done, only samples identified as preserved may be used as proxy of original seawater chemistry (e.g., Brand and Veizer, 1980; Grossman, 1994; Brand, 2004). Some authors prefer to evaluate their complete sample collection as one using a fixed-chemistry approach of high Sr, low Mn and Fe contents (e.g., Joachimski et al., 2004), whereas others use $\mathrm{Mn} / \mathrm{Sr}$ or some other ratios (e.g., Denison et al., 1994; Jacobsen and Kaufman, 1999), while others use similarities in isotopic trends after screening for anomalous elemental and isotopic contents/compositions (e.g., Holser, 1997; Saltzman, 2002) to identify those samples that are least-altered (= not pristine/preserved).

In contrast to the above espoused approach, we prefer to evaluate all samples (brachiopods, matrix, cement) from each and every sample horizon as its own package with its own unique geochemical trends and values that must be considered in conjunction with physical evidence of preservation (e.g., Brand and Veizer,

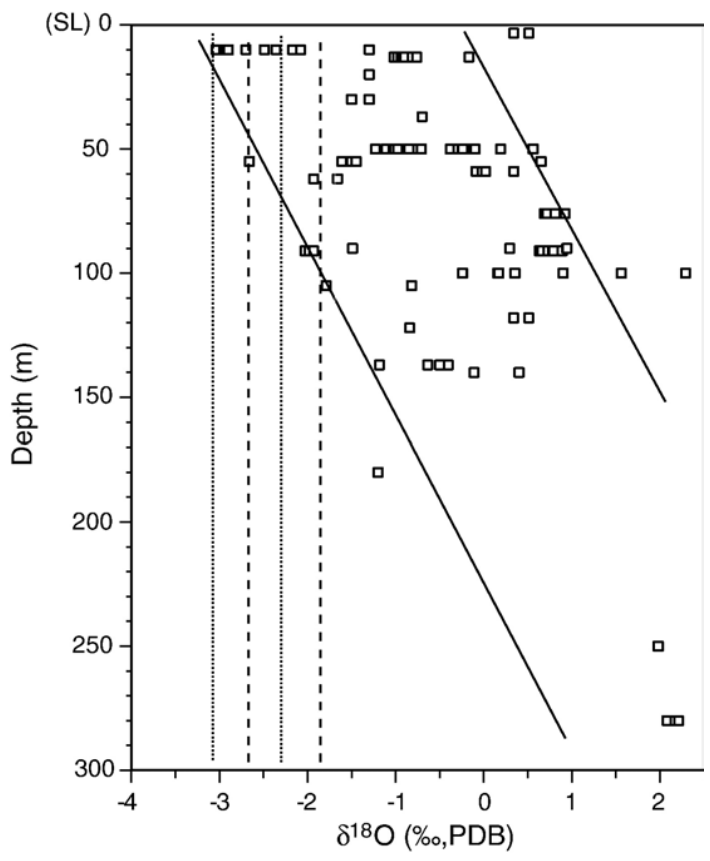

Fig. 7. Oxygen isotope trend with water depth of modern shallowwater low-latitude brachiopods (Brand et al., 2003). The diagonal lines depict the general isotope trend with increasing water depth. The dotted lines represent the upper limit of values for brachiopods inhabiting a depth range from 20 to $70 \mathrm{~m}$, whereas the dashed lines depict the upper limits for the shallowest and deepest representatives of a population from waters of 40-110 m depth. 

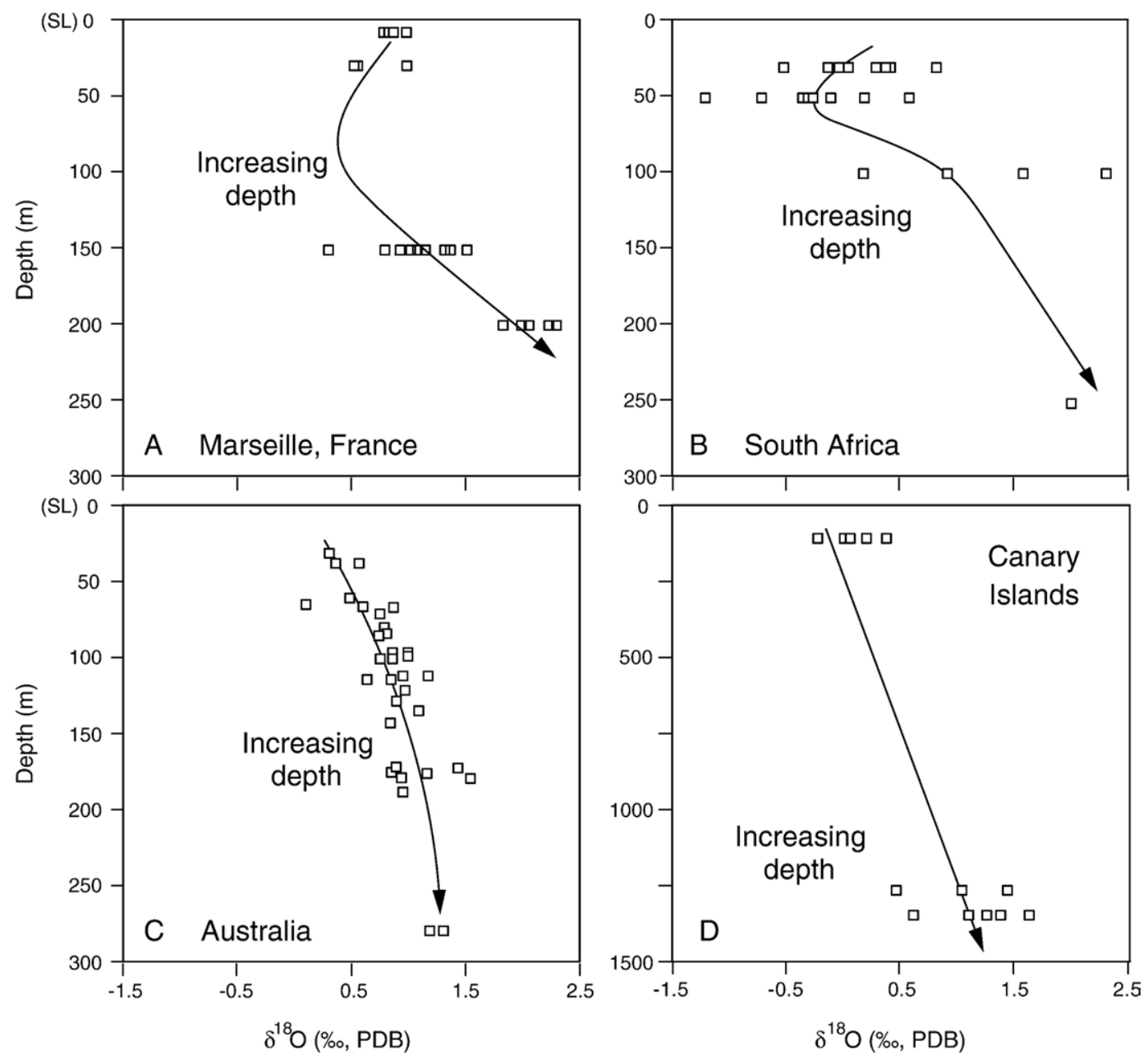

Fig. 8. Oxygen isotope trends of modern brachiopods with increasing water depth from select locations (A, B, D, Brand et al., 2003; C, James et al., 1997). The arrowed-lines depict the general trend of isotope values with water depth.

1980; Bates and Brand, 1991; Brand, 1991, 2004). Neither approach represents a $100 \%$ solution to defining carbonate and/or other components that are preserved in their original composition, but we believe that our approach of detailed individual and collective (within sample set) analysis and comparison coupled with dynamic chemical compositions for each individual horizon sample set is a superior way of identifying preserved material; this will be demonstrated in more detail below for sample sets from three horizons.

Low-Mg calcite (LMC) by virtue of its greater stability is the material of choice for characterizing Paleozoic seawater conditions and thus articulated LMC brachiopods fulfill this criterion (e.g., Bates and Brand, 1991). After subjecting individual samples from a specific horizon to an array of tests, such as no visible discoloration of the shell (e.g., turning white due to loss of optic integrity of fibres), or being coated by desert varnish (iron/manganese hydroxide/oxide), by SEM for the characterization of morphologically well-preserved trabecular fibers in the secondary layer of the shell, and by chemistry of consistent $\mathrm{Sr}, \mathrm{Mg}, \mathrm{Na}, \mathrm{Mn}$, and $\mathrm{Fe}$ contents and $\delta^{13} \mathrm{C}$ and $\delta^{18} \mathrm{O}$ compositions among the brachiopod set, but comparatively distinct from those of the matrix and/or cement (e.g., Brand, 1991, 2004), one should be able to identify those samples that carry an original signature of the ambient seawater. This process is called the Dynamic Elemental Limit (DEL) model, whereas the one espousing 'constant' trace elements contents is referred to as the Static Elemental Limit (SEL) model. The dynamic elemental contents model and its variable limits is similar to those natural variations observed in modern brachiopods (Morrison and Brand, 1986; Brand et al., 2003) and when coupled 


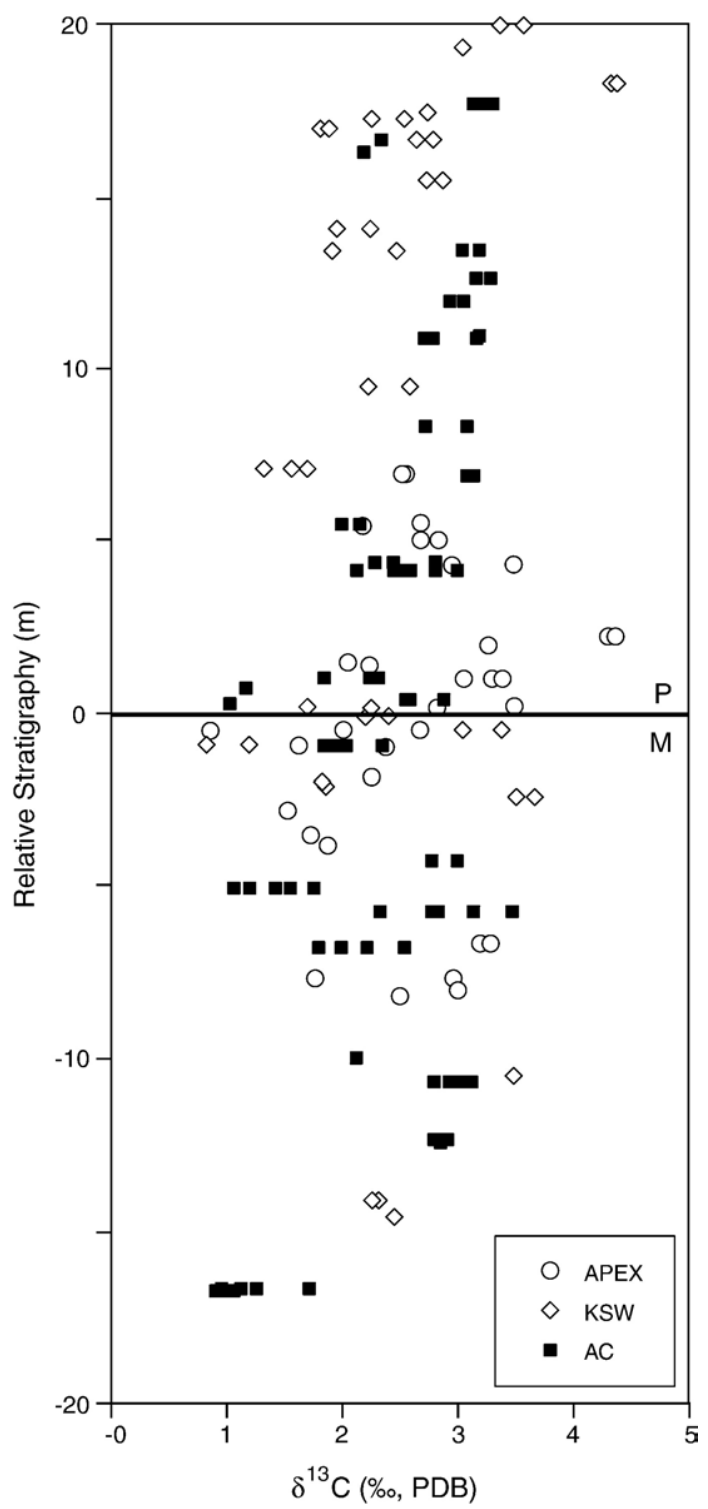

Fig. 9. Carbon isotope trend of pristine brachiopod material from about $( \pm 20 \mathrm{~m})$ the mid-Carboniferous boundary from the Bird Spring Formation at Apex, Kane Springs Wash East and Arrow Canyon, Great Basin, Nevada. The boundary placement as in Fig. 6.

with the evaluation of the population on a horizon-byhorizon basis is the preferred method of determining what is pristine and reflects ecological seawater conditions. The difference in trace and isotope chemistry between brachiopods and concomitant matrix may to a large degree depend on the water/rock ratio of the diagenetic system (cf. Brand and Veizer, 1980, 1981; Marshall, 1992). In some instances, without this one-onone comparison between brachiopod and brachiopod, and/or matrix geochemistry, the identification of unequivocally preserved material may prove to be quite challenging (Brand, 2004). Once all the samples from one horizon are evaluated, the evaluation process is then repeated on all samples (brachiopods, matrix, cement) from the next horizon. Anomalous chemical signals that may be the result of adhering matrix, oxide coatings, etc. on brachiopod shells are generally not a concern because they are easily identified and readily removed from further discussion but maintained in the database (identified by bold font, Appendix).

In the case of the material from Arrow Canyon most of the diagenetic evaluation was completed by a precursor study on the Bird Spring Formation (Brand and Brenckle, 2001). The supplementary samples from Arrow Canyon added in this study were evaluated in the same manner, and only those brachiopod samples deemed well preserved are in used in the construction of subsequent figures and in their discussion except for Fig. 4.

Many brachiopod specimens from the Kane Spring Wash East locality are well preserved, with SEM analysis showing the well-defined trabecular fibers of the secondary layer indicating microstructural preservation (Fig. 3A, B, C), whereas others have fibers showing signs of fusion and 'melting' (Fig. 3D), and in others they are replaced, in part, by coarse diagenetic calcite (Fig. 3E). The microstructural evaluation was followed by the DEL model evaluation of their trace element and stable isotope chemistry, and sample sets from three horizons of the Kane Springs Wash East (2) and Apex (1) were chosen to demonstrate the process and logic in identifying material with 'pristine' chemistry. The first test set, consisting of three brachiopods, one matrix and one cement sample from horizon CSW 14a (Fig. 2), is evaluated for their chemical compositions (Fig. 4A-C,

Table 2

Statistical analysis (one-way ANOVA) of carbon isotopes of preserved brachiopods from the Bird Spring Formation about the midCarboniferous boundary at Apex, Kane Springs Wash East and Arrow Canyon, Great Basin, Nevada

\begin{tabular}{|c|c|c|c|c|c|}
\hline Parameter & Apex & Kane Springs & Arrow Canyon & $\mathrm{p}$ & $\Delta^{13} \mathrm{C}$ \\
\hline \multicolumn{6}{|c|}{ Pennsylvanian } \\
\hline \multirow[t]{3}{*}{$\delta^{13} \mathrm{C}(\% \circ)$} & $+2.96(18)$ & $+2.52(23)$ & - & 0.066 & 0.44 \\
\hline & - & $+2.52(23)$ & +2.63 (41) & 0.531 & 0.11 \\
\hline & +2.96 (18) & - & $+2.63(41)$ & 0.048 & 0.33 \\
\hline \multicolumn{6}{|c|}{ Mississippian } \\
\hline \multirow[t]{3}{*}{$\delta^{13} \mathrm{C}(\% \circ)$} & $2.13(17)$ & $+2.40(14)$ & - & 0.350 & 0.27 \\
\hline & & $+2.40(14)$ & $+2.09(40)$ & 0.224 & 0.31 \\
\hline & $2.13(17)$ & - & $+2.09(40)$ & 0.844 & 0.04 \\
\hline $\mathrm{P}$ & 0.001 & 0.677 & 0.001 & & \\
\hline$\Delta^{13} \mathrm{C}$ & 0.83 & 0.12 & 0.54 & & \\
\hline
\end{tabular}

Significance is at the $95 \%$ confidence level (pb0.050), $\Delta^{13} \mathrm{C}$ is the difference between mean values of pairs, $(\mathrm{N})=$ number of data. 

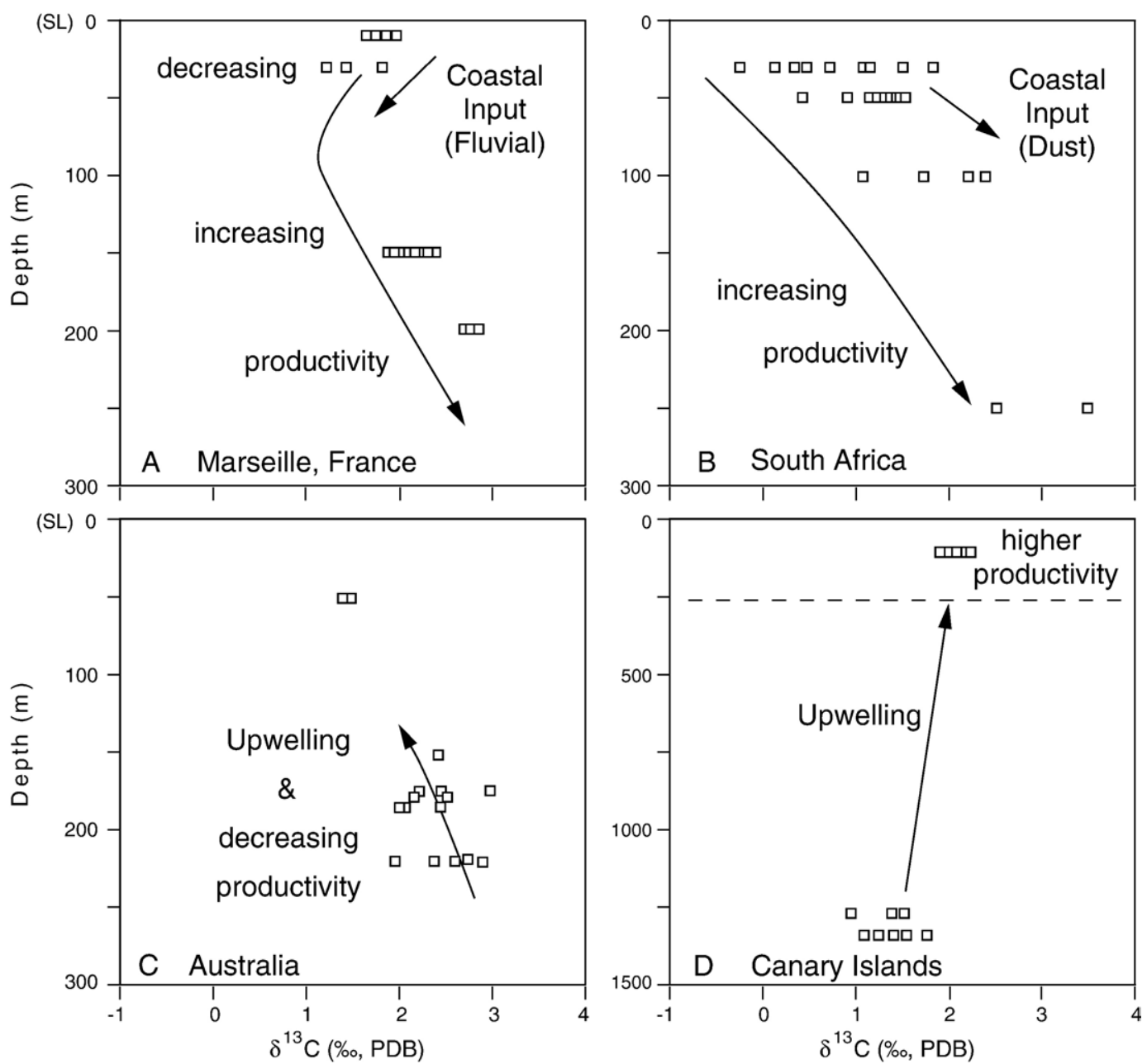

Fig. 10. Carbon isotope trend in modern brachiopods from select localities (A, B, D, Brand et al., 2003; C, James et al., 1997). The lines and text depict the direction and source of the postulated major nutrients and consequently productivity expected in these respective offshore coastal waters.

Appendix). Two of the three brachiopods and the cement are sufficiently high in $\mathrm{Sr}$ to be deemed preserved, whereas the Sr of the third brachiopod and matrix are low (anomalous) and thus deemed altered (Fig. 4A). Furthermore, the same two brachiopod samples identified as preserved are also low in Fe and Mn contents to maintain their classification (Fig. 4B). The third brachiopod and matrix are relatively higher in both $\mathrm{Mn}$ and $\mathrm{Fe}$ and thus continue to be deemed as altered. In contrast, the cement is anomalously high in both $\mathrm{Mn}$ and $\mathrm{Fe}$, which discounts its initial classification as preserved (Fig. 4B). The stable isotope values of relatively consistent and heavy values both for carbon and oxygen supports the assertion that the two brachiopods specimens carry a 'pristine' signal, whereas the third brachiopod, matrix and cement with their anomalously more negative carbon and oxygen isotope values support an altered state (Fig. 4C). The interpretation of a 'pristine' chemical signal by these two brachiopods from horizon CSW 14a at Kane Springs Wash East is also supported by their microstructural evaluation (Fig. 3B), whereas the third brachiopod specimen, matrix and cement are all deemed to be diagenetically altered in their chemical contents/compositions and fabrics.

A second set of samples consisting of two brachiopods, one each of matrix and cement, was chosen from horizon CSW 23 of the Kane Springs Wash East section (Fig. 2). All of the samples are low in Sr (relative to a static limit) but within the expected range for $\mathrm{Mg}$ (Fig. 4D), and thus are probably all altered or preserved. In contrast, only the cement sample is high in Fe and $\mathrm{Mn}$ and thus clearly deemed altered, whereas the brachiopods and matrix fall close to the upper limit for Mn and 


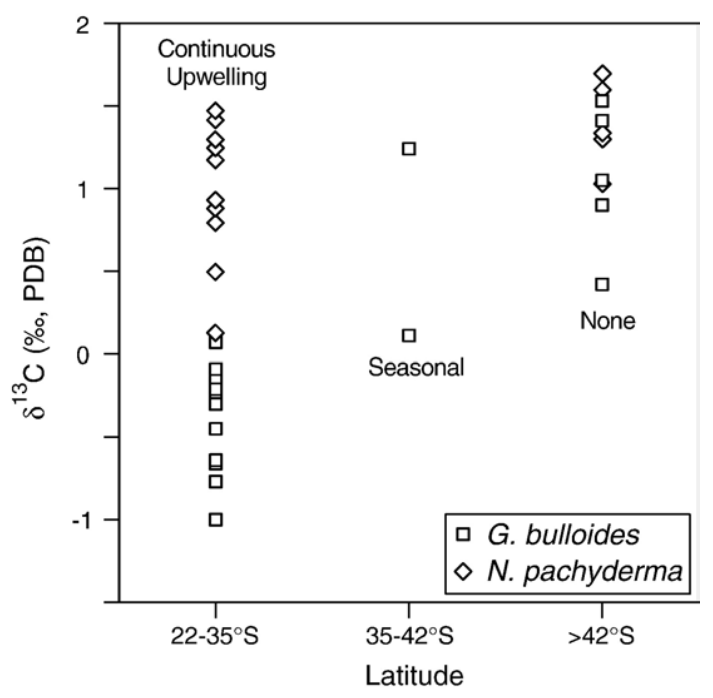

Fig. 11. Carbon isotope compositions of foraminifera (Globigerina bulloides and Neogloboquadrina pachyderma (dex.)) from year-round upwelling, seasonal upwelling and non-upwelling regions along the Peru-Chile coast (Mohtadi et al., 2005).

Fe chemistry observed in modern counterparts (Fig. 4E; Brand et al., 2003), which supports their ambivalent prior classification. Finally, the carbon and oxygen isotope values of the cement are anomalously negative confirming its classification as altered (Fig. 4F). Although, the two brachiopod and matrix samples cluster close together and their previous diagenetic evaluations were ambivalent, their general $\delta^{18} \mathrm{O}$ range from $-6.86 \%$ o to $-7.89 \%$ is considered anomalous, and in conjunction with the altered state of the fibers in the shells of the brachiopods suggests that all of them are altered and do not carry pristine signals (Fig. 4F). Thus none of the material from horizon CSW23 at Kane Springs Wash East is deemed to have preserved its original chemistry and shall not be used in the subsequent discussion.

Overall, evaluation of the brachiopod material from Apex supports the assertion that many specimens have retained the original morphology of fibers of the secondary layer (Fig. 3F, H). In contrast, some specimens experienced extensive replacement of their fibers by diagenetic calcite (Fig. 3G). The results of the chemical evaluation process are presented for one horizon, which exemplifies the approach of the process in outlining and identifying those samples that have suffered degrees of diagenetic alteration.

A group of five samples (two brachiopods, one cement and one matrix in duplicate) from horizon $\mathrm{AX} 2$ ( $-0.5 \mathrm{~m}$ relative to the M/P boundary) of the Bird Spring Formation at Apex depict divergent trace element and stable isotope trends. The brachiopod and cement samples depict $\mathrm{Sr}$ and $\mathrm{Mg}$ contents consistent with a 'preserved' status, whereas the two matrix samples are low in $\mathrm{Sr}$ suggesting intensive diagenetic equilibration (Fig. 4G; cf. Brand and Veizer, 1980). The above interpretations are also supported by the Fe and Mn trends and values for all samples (Fig. 4H). In contrast, the carbon and oxygen isotope values support the classification of preservation for only the two brachiopod samples, and an altered state for the matrix as well as the cement sample (Fig. 4I). This type of evaluation was carried out for all samples used in this study. Consequently, only the material classified as preserved, which includes most of the brachiopod

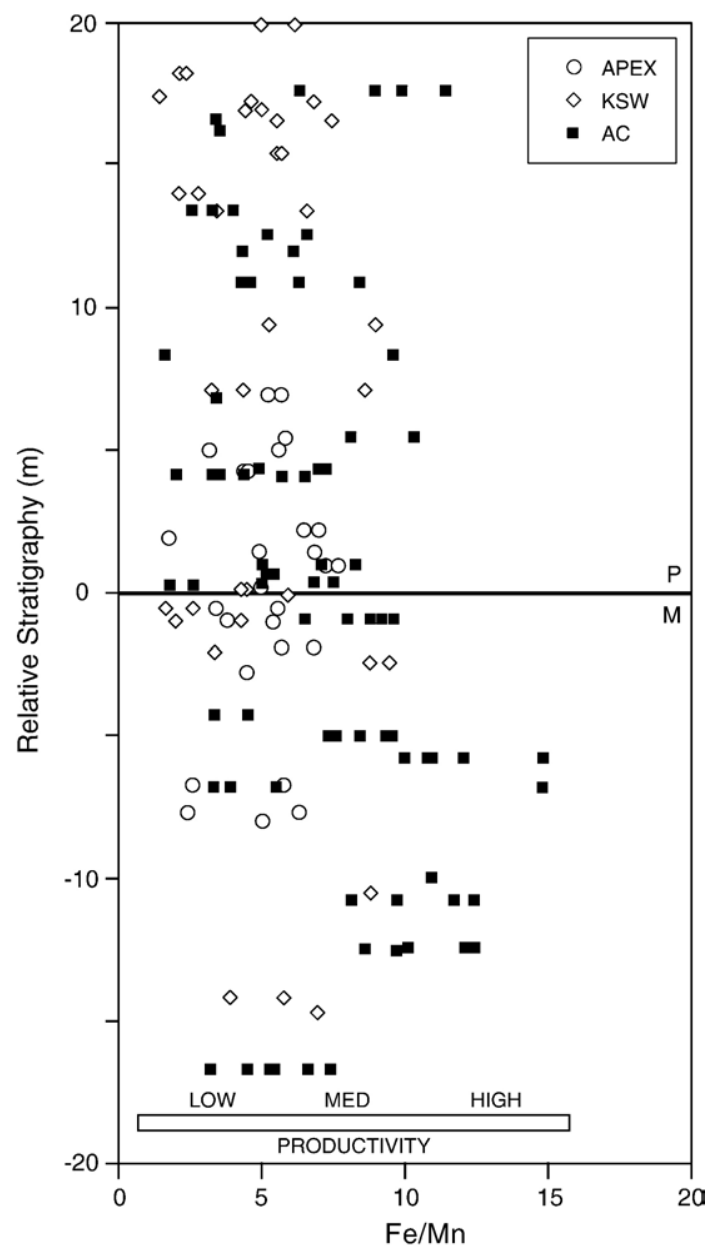

Fig. 12. Fe/Mn ratio of pristine brachiopod material from about $( \pm 20 \mathrm{~m})$ the mid-Carboniferous boundary of the Bird Spring Formation at Apex, Kane Springs Wash East and Arrow Canyon, Great Basin, Nevada. The assignment of 'Productivity' levels is relative to expected trends observed in high nutrient high chlorophylliron enriched and high nutrient low chlorophyll-iron-limited regimes (cf. Bruland and Lohan, 2003). The boundary placement as in Fig. 6. 
Table 3

Statistical analysis (one-way ANOVA) of Fe/Mn (mean weight ratio) of preserved brachiopods from the Bird Spring Formation about the mid-Carboniferous boundary at Apex, Kane Springs Wash East and Arrow Canyon, Great Basin, Nevada

\begin{tabular}{lllll}
\hline Parameter & Apex & Kane Springs & Arrow Canyon & $\mathrm{p}$ \\
\hline \multicolumn{2}{l}{ Pennsylvanian } \\
Fe/Mn & $5.423(15)$ & $4.843(24)$ & - & \\
& - & $4.843(24)$ & $6.135(46)$ & 0.346 \\
& $5.423(15)$ & - & $6.135(46)$ & 0.051 \\
\multicolumn{2}{l}{ Mississippian } & & & \\
Fe/Mn & $4.640(13)$ & $5.210(14)$ & - & 0.492 \\
& - & $5.210(14)$ & $8.723(35)$ & 0.002 \\
& $4.640(13)$ & - & $8.723(35)$ & 0.001 \\
p & 0.186 & 0.627 & 0.001 & \\
\hline
\end{tabular}

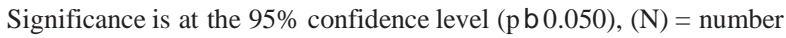
of data.

samples from the three localities of the Bird Spring Formation, will be used for the following paleobathymetric and paleonutrient interpretations and discussion of the southern Great Basin Seaway seawater during Mid-Carboniferous time.

\section{Great Basin seaway}

The seaway of Nevada is part of the Great Basin, which is part of the eastern periphery of the Panthalassa Ocean, and occupied part of the western North American craton during the Mississippian-Pennsylvanian (Fig. 1). The Mississippian-Pennsylvanian boundary is well defined by conodonts in all three successions, and further supported by the concurring $\mathrm{Sr}$ isotope trend based on well-preserved brachiopods from Arrow Canyon, Apex and Kane Springs Wash East. The Sr isotope trend (and band based on the natural variation observed in modern brachiopods, Brand et al., 2003) although relatively invariant for the latest Mississippian as well as the earliest Pennsylvanian, is highlighted by a sharp excursion across the boundary, which is based on the results of material analyzed from Arrow Canyon (Fig. 5). This 'transition' is clearly observed in the Sr isotope results from all three localities, and the strontium isotope results from Kane Springs Wash East and Apex fall well within the established trend without resorting to 'wiggle' matching and adjustments. This emphasizes the reliability and prowess of ${ }^{87} \mathrm{Sr} /{ }^{86} \mathrm{Sr}$ as a first class chemostratigraphic correlation tool if based on material that has been confidently classified as pristine and thus reflecting original and ambient seawater chemistry, as well as being stratigraphically well constrained (measured).

Modern brachiopods and their isotopic compositions, by analogy, will be used to set baseline conditions for deciphering isotope trends in their mid-Carboniferous counterparts. For instance, carbonate $\delta^{18} \mathrm{O}$ values should become enriched in ${ }^{18} \mathrm{O}$ with increasing water depth in modern brachiopods from low-latitudes and shallow-water (b 300 m; Brand et al., 2003). Modern shallow-water and tropical settings record water temperature gradients of about $5{ }^{\circ} \mathrm{C} / 100 \mathrm{~m}$ off the Bahamas and in the Java Sea (Sverdrup et al., 1942; Tomascik and Mah, 1997). Brachiopods, if they incorporate carbonate in oxygen isotopic equilibrium with the ambient water (e.g., Lowenstam, 1961; Bates and Brand, 1991; Carpenter and Lohmann, 1995; Lee and Wan, 2000; Brand et al., 2003), should be good proxies of coeval water conditions with changing water depth and/or temperature (Lécuyer and Allemand, 1999).

In contrast to water depth indicators, almost nothing is known about the productivity of Paleozoic oceans and seas (e.g., Kump and Arthur, 1999; Saltzman, 2002) due to lack of 'good' proxy information relating primary seawater productivity to chemistry in pristine shells of brachiopods. Perhaps, the combination of $\delta^{13} \mathrm{C}$ and the micronutrient such as iron may open up a new venue for evaluating seawater productivity based on brachiopodbased iron similar to the established diatom model (e.g., Bruland et al., 2005; Fasham et al., 2006).

\subsection{Bathymetry}

It should be possible to define bathymetric gradients using oxygen isotope values of preserved brachiopods

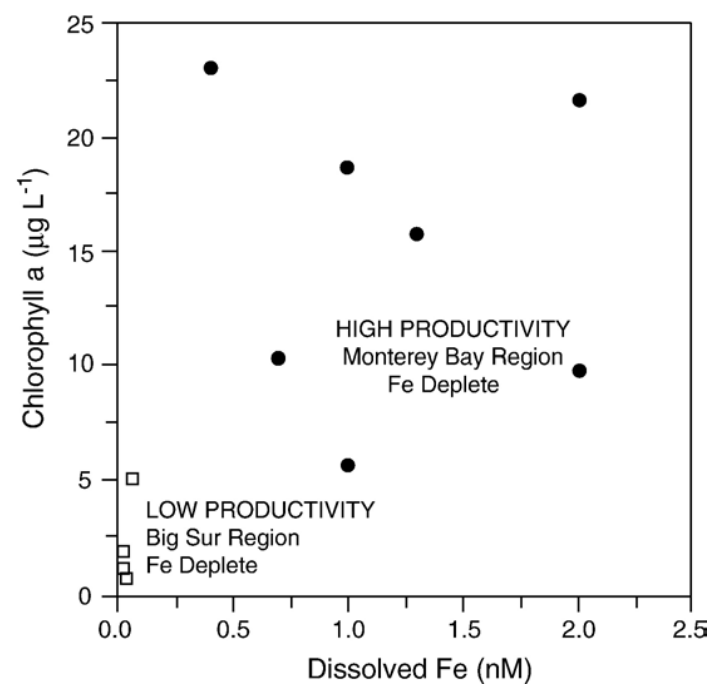

Fig. 13. Dissolved iron concentration in coastal waters relative to chlorophyll a abundance in areas of low productivity (Big Sur region off California) and high productivity (Monterey Bay, California; Bruland et al., 2001). 

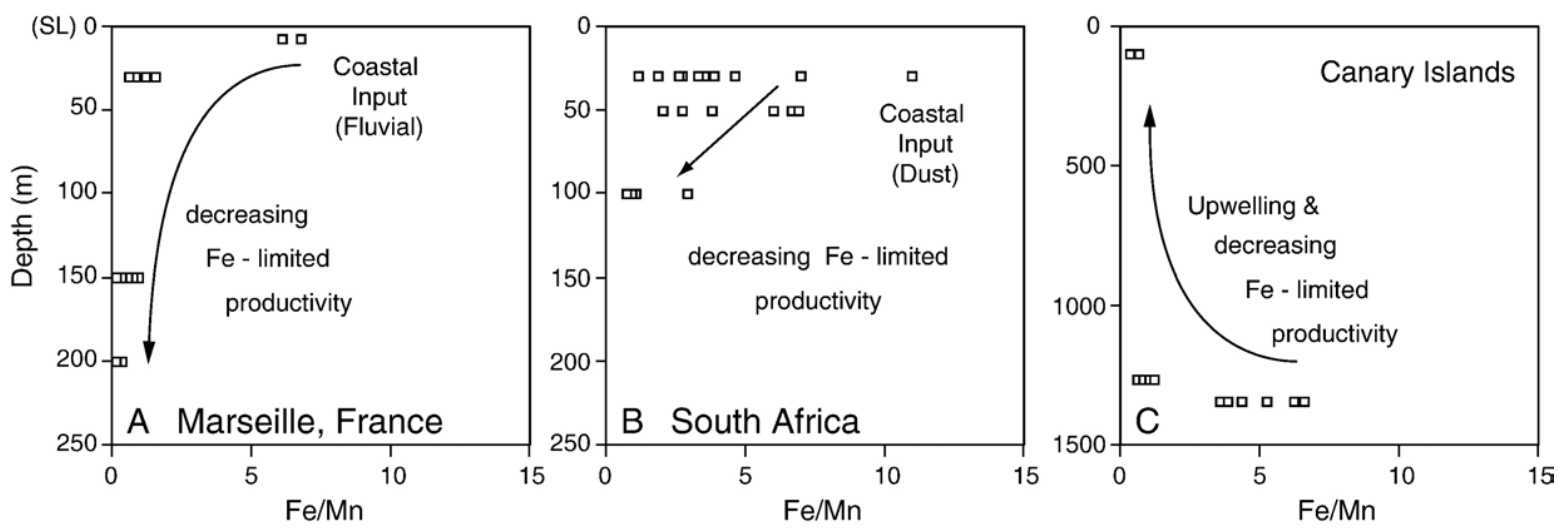

Fig. 14. Fe/Mn ratio changes with water depth of modern mid- and low-latitude brachiopods from off Marseille, South Africa, and the Canary Islands (Brand et al., 2003). For Marseille material, the Fe/Mn variation reflects coastal (fluvial sediment) input of iron by the Rhone River into the Mediterranean Sea (cf. Bruland et al., 2001). In the instance of South Africa, the source of iron to the coastal waters is by dust carried by offshore winds from arid hinterland. In contrast, for the Canary Islands nutrient-enriched (macro- and micro-) upwelling waters are supplying iron to the phytoplankton (above the dashed line - photic zone) and consequently the brachiopods. Habitats further away from nutrient sources and deplete in iron as exhibited by lower ratios (cf. Bruland and Lohan, 2003).

provided they span coeval intervals and lived in habitats with similar environmental conditions (cf. Adlis et al., 1988). Brachiopods were collected from the Bird Spring Formation from within $20 \mathrm{~m}$ of either side of the midCarboniferous boundary at three separate localities, the GSSP at Arrow Canyon (AC), at Apex (Ax) and Kane Springs Wash East (KSW, Fig. 1). With removal of the diagenetically altered material from the database (highlighted in bold in the Appendix), the wellpreserved proxies and their $\delta^{18} \mathrm{O}$ values are plotted and represented by Fig. 6. A slightly sinusoidal trend is evident by the oxygen isotope data from the three localities, with an overall range similar to that observed in modern counterparts (Carpenter and Lohmann, 1995; Brand et al., 2003). The only exception is the large shift in the trend towards more positive $\delta^{18} \mathrm{O}$ values at about $10 \mathrm{~m}$ above the period boundary during the earliest Pennsylvanian (Fig. 6). Overall, the isotope values of brachiopods from Arrow Canyon tend to be more positive than their counterparts from the other two coeval sections. In general terms, it appears to confirm the paleoecological interpretation of a deeper habitat at Arrow Canyon than at the other studied sections. The other slight fluctuations may represent variations in either water temperature or depth or salinity similar to that observed on the Great Bahama Bank (Bathurst, 1975, p. 100).

Detailed statistical analysis reveals some interesting relationship between $\delta^{18} \mathrm{O}$ values of the brachiopods from the three localities. The isotope data of the latest Mississippian brachiopods reveals a significant difference ( $\mathrm{pb} 0.05$; Table 1) in values between specimens from Arrow Canyon (AC) and those from Apex, but none between those from AC and Kane Springs Wash East, and between AC and Apex. In the case of the Apex-Kane Springs Wash East-AC pairings the $\Delta^{18} \mathrm{O}$ is $0.49 \%$ ond $0.30 \%$, respectively. Whereas with $0.79 \%$ it is significant between the dataset from AC and Apex, and because we are dealing with pristine material and thus data in all instances, these isotopic differences must be related to differences in water depth/ temperature between the three localities. Water- ${ }^{18} \mathrm{O}$ and salinity impacts whether of a local and/or secular nature, are discounted because of the relatively close proximity of the three sections, their similar environmental conditions and settings (Section 3) and their coeval temporal disposition (Lécuyer and Allemand, 1999).

The variance in isotopic values increases during the earliest Pennsylvanian with significant differences between the Arrow Canyon data and those from Apex and Kane Springs Wash East (Fig. 6, Table 1). The $\Delta^{18} \mathrm{O}$ differential of the Apex-Kane Springs Wash East set is smaller during the earliest Pennsylvanian compared to that during the latest Mississippian (Table 1). In contrast, the earliest Pennsylvanian $\Delta^{18} \mathrm{O}$ differentials of brachiopods from Kane Springs Wash East and AC and between Apex and AC are greater than of earlier times (Table 1). Again a salinity influence is discounted because of the close proximity, the three localities experienced similar moderate to high energy conditions (Webster, 1969) that would most likely dispel any development of salinity gradients (cf. Bathurst, 1975), and thus impacts on isotopes as observed in modern brachiopods from two drastically divergent and 
separated environments such as the Mediterranean Sea and the Bay of Fundy (Brand et al., 2003).

A comparison of isotope values between the various localities during the latest Mississippian and earliest Pennsylvanian shows some interesting trends (Fig. 6). Overall, there seems to be a change in $\Delta^{18} \mathrm{O}$ of about 0.31 to $0.46 \%$ o between the latest Mississippian and earliest Pennsylvanian in the southern Great Basin of Nevada. (Table 1). Because of their similarity in environments and conditions such as salinity, it appears the depth/temperature differential increased from the latest Mississippian to the earliest Pennsylvanian in the southern part of the Great Basin seaway. In conjunction with the geologic setting and paleoecology of the three localities, the isotope values between the localities support a shallower setting for Apex with a deepening of the seas towards Kane Springs Wash East and AC. Furthermore, the isotope values support an overall deepening and possibly cooling of the seaway from the latest Mississippian through to the earliest Pennsylvanian.

Assigning depths to the isotopic changes observed in the Bird Spring brachiopods of the southern Great Basin is a complex task that is clearly demonstrated by $\delta^{18} \mathrm{O}$ values observed in shallow-water and low-latitude modern brachiopods (Fig. 7; Brand et al., 2003). Nevertheless, with the mean $\delta^{18} \mathrm{O}$ values of Bird Spring brachiopods, and trends based on modern brachiopods (diagonal lines in Fig. 7), it is possible to assign probable depth ranges of about 20-70 $\mathrm{m}$ and 40-100 m for the latest Mississippian (dotted lines) and earliest Pennsylvanian (dashed lines), respectively (Fig. 7) for the southern Great Basin. It appears that the deepening of the southern seaway was about 20-30 m for this time interval (Table 1). A detailed evaluation of trends in modern brachiopods from off Marseille, South Africa, Australia and the Canary Islands confirms the complexity between $\delta^{18} \mathrm{O}$ values and water depth (Fig. 8). In some instances, the topography of the offshore environment as well as fluvial inputs may factor into the environmental process (Fig. 8A), whereas in some instances no major fluvial impacts but surface currents may complicate matters (Fig. 8B). Upwelling currents may present their own challenges in assessing the impact relative to non-upwelling areas of deciphering changes due to water depth versus temperature (Fig. 8C, D). Despite, these complications, it is determined in the absence of fluvial inputs into the Bird Spring sea by virtue of its large carbonate platform (Fig. 1), the relatively similar environments of deposition and energy levels precluded the establishment of significant $\mathrm{pH}$ (Zeebe, 2001) and salinity gradients, and that southern Great Basin sealevel may have fluctuated by about 20 to
$30 \mathrm{~m}$ during the Mid-Carboniferous (Fig. 6). Another possibility is that slightly cooler waters upwelled from the Foreland Basin of the seaway onto the carbonate platform during this time, and thus a combined depth/ temperature control may be responsible for the observed oxygen isotope trends in the Bird Spring brachiopods of the southern Great Basin seaway. Information from additional sites in the Great Basin may resolve some of the outstanding issues of depth and temperature control.

\subsection{Productivity-carbon isotopes}

Deciphering carbon isotope trends in ancient rocks, sediments and brachiopods are still far from being an exact science and open to interpretation as to cause and effects (cf. Kump and Arthur, 1999; Parkinson et al., 2005). Two causes for the observed negative/positive shifts in stratigraphic $\delta^{13} \mathrm{C}_{\text {carbonate }}$ values have been put forth, where 1) "...long-term secular shifts caused by changes in the fractional burial of organic carbon, and 2) transient shifts caused by abrupt changes of biological productivity in the surface photic zone..." (Holser, 1997, p. 173). The trends and oscillations depicted in many studies must be of a global nature to facilitate the use of carbon isotopes as a correlation tool; is this a realistic expectation for something as varied as organic matter burial and/or seawater productivity?

No significant differences or specific trends, except for some minor spikes, were observed in $\delta^{13} \mathrm{C}$ of the brachiopods from the latest Mississippian or the earliest Pennsylvanian of the Bird Spring Formation, southern Great Basin (Fig. 9). This is not unexpected in light of the environmental similarities espoused above for the three localities. Thus, it is difficult to interpret the minor fluctuations in $\delta^{13} \mathrm{C}$ values in terms of changes in either organic matter burial and/or surface-water productivity. The above observations, in part, are confirmed by statistical analysis of the Bird Spring data and they show no significant differences in $\delta^{13} \mathrm{C}$ values for the latest Mississippian results from Apex, Kane Springs Wash East and Arrow Canyon (Table 2). Indeed only small differences, mean value differences range from 0.04 to $0.31 \%$, were noted between the samples from the three localities during the latest Mississippian (Table 2). The situation is similar for the results from the earliest Pennsylvanian, with only one pairing significant at the 95\% confidence level ( $\mathrm{pb} 0.050$ ), although the large disparity in samples $(\mathrm{N})$ between the two datasets $(\mathrm{N}=18$ and $\mathrm{N}=41$ ) may had an influence on the statistical analysis beyond the 'natural' variation (Table 2). In any case, for the earliest Pennsylvanian, the $\Delta^{13} \mathrm{C}$ varies from a low of 0.11 to a high of $0.44 \%$, which agrees with the 
similar environmental conditions persisting at the three localities in the southern Great Basin seaway.

The small $\Delta^{13} \mathrm{C}$ differences from 0.12 to $0.83 \%$ o noted at the three localities between the latest Mississippian and the earliest Pennsylvanian (Table 2) are in discord with the $\Delta^{13} \mathrm{C}$ shifts of about $1.5 \%$ and $3.0 \%$ recorded for the North American mid-continent and the Russian Platform for this apparently similar time interval, respectively (Popp et al., 1986; Mii et al., 1999, 2001). Perhaps, differences in synchronism of sampling strategy (perhaps slightly younger and/or older material used at the other studies), lower density of samples (reflecting differences in natural variation within and between horizon datasets) about the midCarboniferous boundary, or differences in ambient water productivity in these different bodies of water (cf. Thomas, 1979; Minas and Minas, 1992; Bruland et al., 2005) may explain the variance in $\delta^{13} \mathrm{C}$ values of brachiopods from the various localities. If the latter proves to be the correct interpretation, it would seriously challenge the correlation potential of $\delta^{13} \mathrm{C}$ in brachiopods and other carbonate secreting organisms.

The difficulty in reconciling variances between regional and international localities is not limited to ancient carbonate datasets. Modern proxies, the brachiopods, equally exhibit complex trends in $\delta^{13} \mathrm{C}$ from several localities with relatively well-established ecologic parameters. In brachiopods from off Marseille $\delta^{13} \mathrm{C}$ values become lighter with increasing water depth to about $50 \mathrm{~m}$ and distance from the Rhone River delta, followed by subsequently heavier $\delta^{13} \mathrm{C}$ values with depth increasing from 150 to $200 \mathrm{~m}$ (Fig. 10A; Brand et al., 2003). The initial trend of shallow offshore brachiopods is in concord with high productivity sourced by the sediments and waters of the Rhone River. The subsequent increase in $\delta^{13} \mathrm{C}$ values may reflect release of additional nutrients and thus higher primary productivity sourced by the fluvial sediments carried into the canyons and deeper waters off Marseille (Fig. 10A; cf. Mackey et al., 2002). The results of brachiopods from offshore Durban, South Africa are more complicated with progressively more positive $\delta^{13} \mathrm{C}$ values and increasing water depth (Fig. 10B). The east coast of South Africa has a dearth of rivers and thus no immediate source for macronutrients and the limiting micronutrient iron from either river water and/or fluvial sediments. Instead, the offshore surface waters are probably seeded with nutrients by dust driven by offshore blowing winds. The progressively heavier $\delta^{13} \mathrm{C}$ values with water depth suggest an increase in productivity (Fig. 10B) achieving a maximum at a depth of $250 \mathrm{~m}$ probably driven by sinking particulates. This is not unusual, because deep chlorophyll maxima (productivity) may indeed extend down to this level provided some light and nutrients are available for processing by primary producers (cf. Mackay et al., 1997). Furthermore, James et al. (1997) observed a trend in carbon isotopes in the brachiopods from the upwelling area of southern Australia, where the deeper and more productive waters are represented by just slightly heavier values in brachiopods from depths ranging from about 230 to $150 \mathrm{~m}$ than their counterparts from a depth of about $50 \mathrm{~m}$ (Fig. 10C). In contrast, a more complicated trend is discernable in the carbon isotope values in the brachiopods from off the Canary Islands. The deeper specimens, awash in the North African upwelling current, have lighter $\delta^{13} \mathrm{C}$ values than their counterparts from about $100 \mathrm{~m}$ depth (Fig. 10D). In this instance, little to no photosynthetic activity of primary phytoplankton is possible at these deep depths off the Canary's, whereas the shallower waters are not only fed by the upwelling currents but are probably also seeded by dust derived from the arid North Africa. Thus the combination of light and nutrients is a major limiting factor for depth and general distribution of phytoplankton productivity in the oceans (Mackay et al., 1997) where macro- and micro-nutrients may be obtained from several different sources and pathways.

Despite, the apparent direct relationship between $\delta^{13} \mathrm{C}$ values, organic matter burial and application to atmospheric $\mathrm{CO}_{2}$ content from the geologic record (e.g., Kump and Arthur, 1999), this association between modern marine particulate organic matter and plankton and aqueous $\mathrm{CO}_{2}$ have revealed inconsistent results (Pancost et al., 1997; Rau et al., 2001). In one instance the $\delta^{13} \mathrm{C}$ of diatoms is controlled by their growth rate (Pancost et al., 1997), which in turn may be limited by the micronutrient iron (Bruland et al., 2001). Furthermore, a study of primary plankton from areas of continuous through seasonal to non-upwelling reflects some of this complex scenario between $\delta^{13} \mathrm{C}_{\text {carbonate }}$ values and seawater productivity (Mohtadi et al., 2005). They examined foraminifera from three distinct water regimes off Chile and Peru, with the first from an area of continuous upwelling $\left(22^{\circ}-35^{\circ} \mathrm{S}\right)$, followed by those from area of only seasonal upwelling $\left(35^{\circ}-42^{\circ} \mathrm{S}\right)$ and lastly from a non-upwelling area $\left(\mathrm{N} 42^{\circ} \mathrm{S}\right.$, Fig. 11). The results for Globigerina bulloides and Neogloboquadrina pachyderma from a sediment/water interface depth of b673 m were compiled according to the three water regimes along the coasts of Peru and Chile. Off Chile, G. bulloides prefers water depth ranging from the surface down to about $100 \mathrm{~m}$ where phytoplankton density is high, whereas $\mathrm{N}$. pachyderma inhabits water depth ranging from 50 down to $200 \mathrm{~m}$ (Mohtadi et al., 
2005). Primary productivity is higher in the offshore waters south of $39^{\circ} \mathrm{S}$ due to the higher precipitation at these higher latitudes and consequently high river discharge into the ocean (Thomas, 1999). This leads to preferential incorporation of ${ }^{12} \mathrm{C}$ by phytoplankton and ${ }^{13} \mathrm{C}$ enrichment of surface waters, and subsequently to heavier $\delta^{13} \mathrm{C} \%$ in the foraminiferas (analogous to the brachiopods; Kroopnick, 1985). Indeed the shallowerwater $\mathrm{G}$. bulloides from south of $39^{\circ} \mathrm{S}$ exhibit heavier $\delta^{13} \mathrm{C}$ values than their lower latitude counterparts (Fig. 11). Although, the deeper water N. pachyderma also show heavier $\delta^{13} \mathrm{C}$ values in tests from the more productive waters than those from the less productive ones, albeit the difference is significantly less pronounced than those exhibited by G. bulloides (Fig. 11). Thus, the $\delta^{13} \mathrm{C}$ of marine invertebrates and sediments may be 'good' indicators of seawater productivity provided the 'right' conditions of primary production exist throughout the water column. Thus based on the similar $\delta^{13} \mathrm{C}$ values of the latest Mississippian (+ 2.09 to $+2.40 \%$ o) and earliest Pennsylvanian $(+2.52$ to $2.96 \%$ ) brachiopods, seawater productivity was relatively invariant in this part of the southern Great Basin and was similar and lower than that of the North American Midcontinent (+2.2 to 4.4\%o, Mii et al., 1999) and Russian Platform (+2.4 to +5.5\%o, Mii et al., 2001) seaway counterparts, respectively.

\subsection{Productivity-iron micronutrient}

Iron has been identified as a major limiting micronutrient in the productivity of diatom chlorophyll (e.g., Bruland et al., 2001, 2005), and it is proposed here that organisms higher on the foodchain may just retain some of this signal in their body and shell chemistry. Thus brachiopods and their Fe/Mn may serve as a proxy of ironlimited seawater productivity. Indeed, the Fe/Mn ratios of the latest Mississippian brachiopods from the Bird Spring Formation range from 1.66 to 14.8 and of the earliest Pennsylvanian ones range from 1.43 to 11.4 (Fig. 12). Overall, the former brachiopods exhibit a slightly higher range and upper limit than then their later counterparts. It is postulated that the Antler Highlands shedding material into the wide Foreland Basin with its predominantly siliciclastic sediments is the source for the iron micronutrients with the currents washing up on the carbonate platform of the Great Basin seaway (Fig. 1). Thus an ironreplete upwelling regime is influencing the distribution and abundance of brachiopods during this time interval in the southern seaway. A fluvial coastal input source is discounted because for its unproven presence of rivers and/or long distance from the sites of deposition by virtue of an extensive carbonate platform east of the localities and separation by a deep basin to the west (Fig. 1). Further support for an upwelling regime comes from the relative bathymetry of the three locations. The Arrow Canyon interval studied in this paper is deemed the deepest of the three sections based on paleoecology and oxygen isotopes, whereas the Apex locality is deemed the shallowest one (Table 1). Thus a coastal input by aeolian processes of winds sourcing Fe from the Antler Highlands should be reflected by highest $\mathrm{Fe} / \mathrm{Mn}$ ratios in the brachiopods from Apex. In contrast an upwelling regime influenced by $\mathrm{Fe}$ sourced from siliciclastic sediments discharged into the Foreland Basin from the western highlands and onto the plateau edge should be reflected by higher $\mathrm{Fe} / \mathrm{Mn}$ in brachiopods from the deepest of the three locales (Fig. 12). The latter is indeed born out by the statistical evaluation of the Fe/Mn data for the brachiopods from the three locations. The Arrow Canyon brachiopods record the highest Fe/Mn during the latest Mississippian as well as the earliest Pennsylvanian (Table 3). In three out of four instances, the Fe/Mn of the Arrow Canyon material is significantly different and higher from those recorded in their shallower-water counterparts (Table 3). Furthermore, the means (Table 3) and ranges (1.43 to 14.8) of Fe/Mn in the Bird Spring brachiopods are similar to those recorded in modern brachiopods off the southwestern tip of Florida (12.0) and Brazil (1.9-6.0; Brand et al., 2003).

The decrease in the overall magnitude of the Fe/Mn ratios from the latest Mississippian to the earliest Pennsylvanian, in light of a generally cooling/deeper scenario, invokes a weakening of the supply of the iron micronutrient with time and thus iron-limited productivity of the southern Great Basin seaway (Fig. 12, Table 3). The change in iron-limiting productivity and general productivity agrees for the $\mathrm{Fe} / \mathrm{Mn}$ and $\delta^{13} \mathrm{C}$ results at Apex and Kane Springs Wash East, but is at odds with their respective results from Arrow Canyon (Tables 2, 3). The following discussion attempts to shed some light on what controls general and iron-limited productivity.

Iron is a limiting micronutrient for diatoms in the waters off California and in other bodies of water (e.g., Bruland et al., 2001; Moore et al., 2002; Bruland et al., 2005). Iron and other nutrients are usually supplied by the upwelling of offshore subsurface waters interacting with organic-rich shelf sediments, whereas it is quite possible for upwelling currents to be iron-deplete if no and/or small plateau/shelf sources of sediment are within the area. However, the supply of oceanic-derived $\mathrm{Fe}$ and nutrients may be augmented by other sources such as aeolian and/or fluvial inputs (Bruland et al., 2001). Furthermore, a broad continental shelf may act as 
an 'iron trap' for these fluvial inputs, where the nearshore sediments are a major source of Fe entrained in upwelling water throughout the year (e.g., Monterey Bay, Fig. 13). In contrast, in areas with a small or narrow shelf insignificant sediment and consequently low $\mathrm{Fe}$ accumulation takes place, and thus, there is limited amount of $\mathrm{Fe}$ available to complement the macronutrients (e.g., Big Sur, Fig. 13). According to Bruland et al. (2001, 2005), Fe-enriched areas are characterized by larger and greater abundances of diatoms than those areas that are Fe-depleted (Fig. 13), which should have repercussions up the foodchain (Smetacek, 1998) and with it a possible impact on brachiopod abundance and shell chemistry.

If this hypothesis is acceptable, then Fe of modern brachiopods just as diatoms should be a recorder of seawater iron-limited productivity. Modern articulated brachiopods off Marseille, South Africa and the Canary Islands may be suitable material to test this hypothesis and their Fe contents as proxies of oceanic iron-limited productivity. The brachiopods from off Marseille were collected at varying water depths in Mediterranean waters off the Rhone River delta, and they should serve as a good model of coastal input and distribution of Fe in offshore waters. Sediments carried by the Rhone River should be iron-enriched and help fertilize the near-shore waters with diminishing impacts farther offshore and those at greater depths. The plot of the Fe/Mn ratio in the Marseille brachiopods shows the expected decrease in Fe with increasing distance and depth from the river delta (Fig. 14A). This pattern of diminishing Fe impact by coastal input with vertical and lateral distance from the source is analogous to that recorded in diatoms off California (e.g., Bruland et al., 2001) and due to flocculation (Sholkovitz and Copeland, 1983).

The coast of Durban, South Africa, unlike the waters off Marseille, has no major river systems and thus offshore fertilization depends largely on offshore blowing winds transporting aeolian material from the arid hinterland (Moore et al., 2002). The shallowerwater brachiopods off Durban are enriched in Fe relative to their deeper water counterparts (Fig. 14B). This is not unexpected for the vertical distribution of iron-rich material deposited on surface waters and their rapid removal by flocculation and biological activity (Bruland and Lohan, 2003).

The brachiopod material from off the Canary Islands serves to demonstrate the impact of both Fe-replete upwelling waters on Fe/Mn shell chemistry (cf. Bruland et al., 2005). Fig. 14C shows the distribution of Fe/Mn in brachiopods from off the Canary Islands, where the cool nutrient-rich Canary Current traverses this area and on down the African coast towards the Cape Verde Islands and west into the Atlantic Ocean. However off the Canary Islands, the plateau/shelf area is small and thus quite possibly subject to less deposition and accumulation of aeolian material (cf. Big Sur, Fig. 13). The brachiopods from the deepest locality are relatively high in $\mathrm{Fe} / \mathrm{Mn}$, with lower values in counterparts from decreasing water depths, which is possibly related to scavenging processes (Fig. 14C).

Overall, modern low-latitude, shallow-water articulated brachiopods contain $\mathrm{Fe} / \mathrm{Mn}$ ratios between 0.33 and 12.0 (Brand et al., 2003). Generally, brachiopods from areas of low productivity and Fe availability such as off Barbados have $\mathrm{Fe} / \mathrm{Mn}$ ratios ranging from 0.33 to 0.81 . In contrast, brachiopods from off Brazil, an active upwelling regime, exhibit $\mathrm{Fe} / \mathrm{Mn}$ ratios ranging from 1.9 to 6.0 for specimens from a depth of $90 \mathrm{~m}$. Other specimens from off Florida (Cape Sable) and the Dry Tortugas, under the possible influence of sediments derived from the Mississippi River and/or Everglades, exhibit relatively high Fe contents with $\mathrm{Fe} / \mathrm{Mn}$ ranging from 5.0 to 12.0 (Brand et al., 2003). Thus the brachiopod Fe/Mn ratios show a wide range of iron-limiting productivity for the waters of the southern Great Basin at Apex, Kane Springs Wash East, and Arrow Canyon during the midCarboniferous.

\section{Conclusions}

Detailed evaluation of pristine brachiopods from the mid-Carboniferous Bird Spring Formation from three localities in southern Nevada suggest the following conclusions:

1) oxygen isotopes are in general agreement with stratigraphic, sedimentologic and paleontologic information suggesting a bathymetric gradient of increasing water depth from south to north in the southern Great Basin,

2) the isotope data support an increase in overall water depth and/or decrease in water temperatures of the southern Great Basin seaway from the latest Mississippian $\left(x=-2.66 \%\right.$, $\left.\delta^{18} \mathrm{O}\right)$ to the earliest Pennsylvanian $\left(\mathrm{x}=-2.27 \%\right.$ o, $\left.\delta^{18} \mathrm{O}\right)$,

3) the latest Mississippian-earliest Pennsylvanian $\Delta^{13} \mathrm{C}$ differential of $0.50 \%$ or the southern Great Basin seaway of Nevada is significantly lower than the transition values for brachiopod populations from the North American Midcontinent of $1.5 \%$ and the Russian Platform of 3.0\%,

4) the difference in $\delta^{13} \mathrm{C}$ values of pristine brachiopods from the Great Basin, NA Midcontinent and Russian 
Platform are ascribed to sample asynchronism and/or variations in general seawater productivity,

5) the $\mathrm{Fe} / \mathrm{Mn}$ ratio of modern brachiopods appears to reflect the productivity of ambient seawater and by evaluating their habitat and geography may indicate the source of the limiting micronutrient iron,

6) the $\mathrm{Fe} / \mathrm{Mn}$ ratios in the brachiopods from the three localities of the Bird Spring Formation of the southern Great Basin seaway support high variation of iron-limited productivity of the ambient waters, and

7) the Antler Orogenic Highlands via the Foreland Basin through upwelling currents was the source for the iron-limiting micronutrient productivity of the shelf- edge of carbonate platform of the southern Great Basin.

\section{Acknowledgements}

Special thanks to M. Lozon and G. Hooper (Brock University) for drafting the figures and the SEM work, respectively. We also thank the reviewers Drs. I. Montanez and D. Katz, and the special volume editor Dr. M. Pope for their incisive comments on the first draft of this manuscript. The authors acknowledge the Natural Sciences and Engineering Research Council of Canada (NSERC) for Discovery Grants (to UB \& AL).

\section{Appendix A}

Geochemical data of Arrow Canyon (new results), Kane Springs Wash East, and Apex (Great Basin, Nevada) brachiopods, matrix and cement; trace element data are in ppm (mg/kg), and stable isotopes are in \%o (PDB). Diagenetically altered samples based on $\mathrm{Mn}$ and Fe trends are in bold font. Strontium isotope data are corrected to a nominal value of 0.710240 for NBS 987 .

\begin{tabular}{|c|c|c|c|c|c|c|c|c|c|c|c|c|c|c|}
\hline Sample \# & Allochem & Horizon & Formation & Location & $\begin{array}{l}\mathrm{Ca} \\
\mathrm{ppm}\end{array}$ & $\begin{array}{l}\mathrm{Mg} \\
\mathrm{ppm}\end{array}$ & $\begin{array}{l}\mathrm{Sr} \\
\mathrm{ppm}\end{array}$ & $\begin{array}{l}\mathrm{Na} \\
\mathrm{ppm}\end{array}$ & $\begin{array}{l}\mathrm{Mn} \\
\mathrm{ppm}\end{array}$ & $\begin{array}{l}\mathrm{Fe} \\
\mathrm{ppm}\end{array}$ & $\mathrm{Fe} / \mathrm{Mn}$ & $\begin{array}{l}\delta^{13} \mathrm{C} \\
\% 0\end{array}$ & $\begin{array}{l}\delta^{18} \mathrm{O} \\
\% \circ\end{array}$ & ${ }^{87} \mathrm{Sr} /{ }^{86} \mathrm{Sr}$ \\
\hline AC8-10 & Brach frag & A52 & $\begin{array}{l}\text { Bird } \\
\text { Spring }\end{array}$ & $\begin{array}{l}\text { Arrow } \\
\text { Canyon }\end{array}$ & 396293 & 761 & 786 & 890 & 8 & 36 & 4.50 & 2.95 & -1.55 & 0.708151 \\
\hline AC8-11 & W & $\begin{array}{l}+0.65 \text { to } \\
+0.80 \mathrm{~m}\end{array}$ & W & W & 379199 & 801 & 861 & 1038 & 10 & 33 & 3.30 & 2.73 & -2.02 & \\
\hline A59-1 & Brach frag & A59 0.00 & $\begin{array}{l}\text { Bird } \\
\text { Spring }\end{array}$ & $\begin{array}{l}\text { Arrow } \\
\text { Canyon }\end{array}$ & 376890 & 3110 & 527 & 1283 & 11 & 113 & & 2.09 & -1.23 & \\
\hline A59-2 & Brach & W & W & W & 376209 & 3791 & 552 & 1120 & 12 & 181 & & & & \\
\hline A59-3m & matrix & W & W & W & 377076 & 2924 & 287 & 840 & 28 & 104 & & 2.12 & -2.99 & \\
\hline A59-4 & Brach frag & W & W & W & 376594 & 3406 & 612 & 1156 & 8 & 65 & 8.13 & 1.93 & -1.33 & \\
\hline A59A-9 & Brach frag & $\begin{array}{l}\text { A59+ } \\
58.4 \mathrm{~cm}\end{array}$ & $\begin{array}{l}\text { Bird } \\
\text { Spring }\end{array}$ & $\begin{array}{l}\text { Arrow } \\
\text { Canyon }\end{array}$ & 389258 & 1023 & 958 & 1161 & 9 & 30 & 3.33 & & & \\
\hline A59A-12 & Brach frag & W & W & W & 379132 & 868 & 905 & 1148 & 7 & 24 & 3.43 & 3.10 & -1.96 & 0.708228 \\
\hline A59A-13m & matrix & W & W & W & 376785 & 3215 & 586 & 1247 & 43 & 186 & & 2.08 & -3.22 & \\
\hline A61-17 & Brach frag & $\begin{array}{l}\text { A61- } \\
20.3 \mathrm{~cm}\end{array}$ & $\begin{array}{l}\text { Bird } \\
\text { Spring }\end{array}$ & $\begin{array}{l}\text { Arrow } \\
\text { Canyon }\end{array}$ & 378293 & 1707 & 597 & 1173 & 57 & 391 & & & & \\
\hline A61-18m & Matrix & W & W & W & 376144 & 3856 & 415 & 470 & 26 & 122 & & 1.63 & -3.75 & \\
\hline A61-19 & Brach frag & W & W & W & 377377 & 2623 & 333 & 2018 & 348 & 549 & & 2.67 & -2.33 & \\
\hline A61-20 & Brach frag & W & W & W & 377932 & 2068 & 329 & 3314 & 42 & 404 & 9.61 & 3.03 & -2.12 & \\
\hline A63-21 & Spiriferid sp. & $\begin{array}{l}\text { A63- } \\
60.96 \mathrm{~cm}\end{array}$ & $\begin{array}{l}\text { Bird } \\
\text { Spring }\end{array}$ & $\begin{array}{l}\text { Arrow } \\
\text { Canyon }\end{array}$ & 379134 & 866 & 695 & 1174 & 6 & 38 & 6.33 & 3.14 & -1.45 & \\
\hline A63-22m & Matrix & W & W & W & 375888 & 4112 & 506 & 1100 & 29 & 145 & & & & \\
\hline A63-23m & Matrix & W & W & W & 375963 & 4037 & 393 & 522 & 380 & 197 & & 0.85 & -4.70 & \\
\hline A63-24 & Rugoclostus sp. & W & W & W & 377178 & 2822 & 372 & 4683 & 148 & 847 & & & & \\
\hline A63-25 & W & W & W & W & 378299 & 1701 & 288 & 830 & 43 & 227 & & 1.21 & -6.90 & \\
\hline A63-26 & W & W & W & W & 378141 & 1859 & 690 & 938 & 12 & 83 & 6.91 & 2.36 & -3.84 & \\
\hline A63-27 & Rugoclostus sp. & W & W & W & 377849 & 2151 & 458 & 1004 & 28 & 120 & 4.29 & & & \\
\hline A64A-28 & Spiriferid sp. & $\begin{array}{l}\text { A64- } \\
38.1 \mathrm{~cm}\end{array}$ & $\begin{array}{l}\text { Bird } \\
\text { Spring }\end{array}$ & $\begin{array}{l}\text { Arrow } \\
\text { Canyon }\end{array}$ & 379372 & 628 & 725 & 1070 & 5 & 26 & 5.20 & 3.12 & -0.94 & 0.708242 \\
\hline A64A-29m & Matrix & W & W & W & 375142 & 4858 & 533 & 847 & 139 & 190 & & 2.24 & -3.11 & \\
\hline A64A-30 & Spiriferid & W & W & W & 379521 & 695 & 808 & 1390 & 6 & 40 & 6.67 & 3.24 & -1.41 & \\
\hline A63B-34m & Matrix & $\begin{array}{l}\mathrm{A} 63+ \\
45.72 \mathrm{~cm}\end{array}$ & $\begin{array}{l}\text { Bird } \\
\text { Spring }\end{array}$ & $\begin{array}{l}\text { Arrow } \\
\text { Canyon }\end{array}$ & 375896 & 4104 & 412 & 456 & 16 & 76 & & 2.60 & -2.63 & \\
\hline A63B-35 & Spiriferid sp. & W & W & W & 377701 & 1356 & 536 & 1733 & 6 & 27 & 4.50 & & & \\
\hline
\end{tabular}


Appendix A (continued)

\begin{tabular}{|c|c|c|c|c|c|c|c|c|c|c|c|c|c|c|}
\hline Sample \# & Allochem & Horizon & Formation & Location & $\begin{array}{l}\text { Ca } \\
\text { ppm }\end{array}$ & $\begin{array}{l}\mathrm{Mg} \\
\mathrm{ppm}\end{array}$ & $\begin{array}{l}\text { Sr } \\
\mathrm{ppm}\end{array}$ & $\begin{array}{l}\mathrm{Na} \\
\mathrm{ppm}\end{array}$ & $\begin{array}{l}\text { Mn } \\
\text { ppm }\end{array}$ & $\begin{array}{l}\text { Fe } \\
\text { ppm }\end{array}$ & $\mathrm{Fe} / \mathrm{Mn}$ & $\begin{array}{l}\delta^{13} \mathrm{C} \\
\%\end{array}$ & $\begin{array}{l}\delta^{18} \mathrm{O} \\
\% \circ\end{array}$ & ${ }^{87} \mathrm{Sr} /{ }^{86} \mathrm{Sr}$ \\
\hline A63B-36 & $\bar{W}$ & $\bar{W}$ & $\overline{~ W W}$ & $\overline{W W}$ & 379062 & 938 & 547 & 923 & 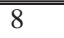 & 49 & 6.13 & 2.88 & -0.40 & \\
\hline A63B-37 & Spiriferid sp. & W & W & W & 379355 & 645 & 508 & 933 & 7 & 30 & 4.29 & 3.00 & 0.06 & \\
\hline A63C-38m & Matrix & $\begin{array}{l}\text { A63- } \\
63.5 \mathrm{~cm}\end{array}$ & $\begin{array}{l}\text { Bird } \\
\text { Spring }\end{array}$ & $\begin{array}{l}\text { Arrow } \\
\text { Canyon }\end{array}$ & 375233 & 4767 & 561 & 4479 & 42 & 538 & & 1.99 & -3.72 & \\
\hline A63C-39 & Spiriferid sp. & W & W & W & 379287 & 713 & 543 & 850 & 11 & 51 & 4.63 & 3.12 & -0.39 & \\
\hline A63C-40 & W & W & W & W & 379105 & 895 & 592 & 710 & 8 & 67 & 8.38 & 2.67 & -0.15 & \\
\hline A63C-45 & Spiriferid & W & W & W & 379470 & 530 & 521 & 849 & 14 & 61 & 4.36 & 2.74 & 0.55 & 0.708243 \\
\hline A66-46 & Rugoclostus sp. & $\begin{array}{l}\text { A66- } \\
40.64 \mathrm{~cm}\end{array}$ & $\begin{array}{l}\text { Bird } \\
\text { Spring }\end{array}$ & $\begin{array}{l}\text { Arrow } \\
\text { Canyon }\end{array}$ & 376696 & 3304 & 460 & 3291 & 50 & 565 & & & & \\
\hline A66-47m & Matrix & W & W & W & 373284 & 6716 & 581 & 942 & 30 & 602 & & 2.00 & -3.03 & \\
\hline A66-48 & Rugoclostus sp. & W & W & W & 375570 & 4430 & 448 & 784 & 20 & 434 & & & & \\
\hline A66-49 & W & W & W & W & 375436 & 4564 & 527 & 1760 & 29 & 366 & 12.62 & 2.15 & -3.58 & \\
\hline A66-52 & Rugoclostus sp. & W & W & W & 378061 & 1939 & 313 & 1377 & 38 & 289 & 7.61 & 2.42 & -3.82 & \\
\hline A66B-53 & Rugoclostus sp. & $\begin{array}{l}\mathrm{A} 66+ \\
25.40 \mathrm{~cm}\end{array}$ & $\begin{array}{l}\text { Bird } \\
\text { Spring }\end{array}$ & $\begin{array}{l}\text { Arrow } \\
\text { Canyon }\end{array}$ & & & & & & & & 1.11 & -4.56 & \\
\hline A66B-57m & Matrix & W & W & W & 377019 & 2981 & 481 & 326 & 14 & 89 & 6.35 & 2.98 & -2.24 & \\
\hline A66B-58 & Rugoclostus sp. & W & W & W & 377049 & 2951 & 488 & 2225 & 217 & 819 & & 2.21 & -3.13 & \\
\hline A66B-61 & Rugoclostus sp. & W & W & W & 378783 & 1287 & 568 & 891 & 12 & 42 & 3.50 & 2.13 & -1.87 & 0.708225 \\
\hline A66C-62 & Rugoclostus sp. & $\begin{array}{l}\mathrm{A} 66+ \\
60.96 \mathrm{~cm}\end{array}$ & $\begin{array}{l}\text { Bird } \\
\text { Spring }\end{array}$ & $\begin{array}{l}\text { Arrow } \\
\text { Canyon }\end{array}$ & 389227 & 1387 & 642 & 1025 & 7 & 36 & 5.14 & & & \\
\hline A66C-64 & Rugoclostus sp. & W & W & W & 378168 & 1832 & 584 & 1322 & 144 & 143 & & & & \\
\hline A66C-65 & W & W & W & W & 378210 & 1790 & 576 & 1135 & 146 & 148 & & 2.40 & -2.91 & \\
\hline A66C-66c & $\begin{array}{l}\text { Internal } \\
\text { cement }\end{array}$ & W & W & W & 415492 & 1902 & 204 & 73 & 16 & 142 & & 2.48 & -4.18 & \\
\hline A66C-67m & Matrix & W & W & W & 376923 & 3077 & 359 & 182 & 12 & 210 & & 3.37 & -2.04 & \\
\hline A66C-71 & Rugoclostus sp. & W & W & W & 401631 & 3405 & 610 & 820 & 7 & 24 & 3.43 & 2.28 & -1.71 & 0.708233 \\
\hline CSW1-1 & Spiriferid & +19.98 m & $\begin{array}{l}\text { Bird } \\
\text { Spring }\end{array}$ & $\begin{array}{l}\text { Kane Springs } \\
\text { Wash E }\end{array}$ & 375644 & 528 & 697 & 669 & 7 & 43 & 6.14 & 3.54 & -2.29 & 0.708229 \\
\hline CSW1-2 & W & W & W & W & 386277 & 631 & 715 & 540 & 6 & 26 & 4.33 & & & \\
\hline CSW1-3 & W & W & W & W & 373511 & 544 & 684 & 604 & 6 & 30 & 5.00 & 3.33 & -2.27 & \\
\hline CSW1-6 & Matrix & W & W & W & 379977 & 2677 & 389 & 273 & 43 & 439 & & 1.16 & -6.09 & \\
\hline CSW2-7 & Productid & $+19.28 \mathrm{~m}$ & $\begin{array}{l}\text { Bird } \\
\text { Spring }\end{array}$ & $\begin{array}{l}\text { Kane Springs } \\
\text { Wash E }\end{array}$ & 372465 & 1563 & 612 & 582 & 10 & 1016 & & 3.00 & -3.44 & \\
\hline CSW2-8 & W & W & W & W & 368711 & 2382 & 610 & 1858 & 19 & 289 & & & & \\
\hline CSW2-10 & Matrix & W & W & W & 362941 & 3306 & 339 & 426 & 25 & 169 & & 1.44 & -4.97 & \\
\hline CSW3-11 & Spiriferid & +18.23 m & $\begin{array}{l}\text { Bird } \\
\text { Spring }\end{array}$ & $\begin{array}{l}\text { Kane Springs } \\
\text { Wash E }\end{array}$ & 361775 & 938 & 679 & 986 & 11 & 24 & 2.18 & 4.35 & -2.25 & \\
\hline CSW3-12 & W & W & W & W & 372052 & 877 & 748 & 986 & 9 & 21 & 2.33 & 4.31 & -2.14 & \\
\hline CSW3-14 & Matrix & W & W & W & 365444 & 3167 & 329 & 447 & 39 & 319 & & 1.81 & -4.93 & \\
\hline CSW4-15 & Brach frag & $+17.38 \mathrm{~m}$ & $\begin{array}{l}\text { Bird } \\
\text { Spring }\end{array}$ & $\begin{array}{l}\text { Kane Springs } \\
\text { Wash E }\end{array}$ & 394747 & 2545 & 579 & 813 & 14 & 20 & 1.43 & 2.69 & -0.59 & \\
\hline CSW4-17 & W & W & W & W & 374146 & 3373 & 623 & 825 & 8 & 20 & 2.50 & & & \\
\hline CSW4-19 & W & W & W & W & 363402 & 1642 & 630 & 1563 & 15 & 214 & & 1.55 & -3.44 & \\
\hline CSW4-18 & Matrix & W & W & W & 383429 & 2569 & 338 & 736 & 28 & 259 & & 1.95 & -4.79 & \\
\hline CSW5-21 & Cement & $+17.23 \mathrm{~m}$ & $\begin{array}{l}\text { Bird } \\
\text { Spring }\end{array}$ & $\begin{array}{l}\text { Kane Springs } \\
\text { Wash E }\end{array}$ & 390906 & 2004 & 470 & 556 & 37 & 212 & & 2.25 & -5.36 & \\
\hline CSW5-22 & Matrix & W & W & W & 382507 & 2805 & 292 & 404 & 26 & 267 & & 2.42 & -4.01 & \\
\hline CSW5-23 & Brach frag & W & W & W & 369801 & 2083 & 486 & 580 & 7 & 48 & 6.86 & 2.48 & -2.18 & \\
\hline CSW5-24 & W & W & W & W & 391147 & 3841 & 620 & 826 & 8 & 37 & 4.62 & 2.19 & -2.32 & \\
\hline CSW6-25 & Brach frag & $+16.93 \mathrm{~m}$ & $\begin{array}{l}\text { Bird } \\
\text { Spring }\end{array}$ & $\begin{array}{l}\text { Kane Springs } \\
\text { Wash E }\end{array}$ & 388947 & 3415 & 632 & 844 & 7 & 31 & 4.43 & 1.82 & -2.48 & 0.708225 \\
\hline CSW6-27 & W & W & W & W & 389325 & 2096 & 587 & 577 & 9 & 45 & 5.00 & 1.74 & -2.67 & \\
\hline CSW6-28 & Cement & W & W & W & 382558 & 1013 & 100 & 54 & 21 & 29 & & 1.31 & -4.78 & \\
\hline CSW6-29 & Matrix & W & W & W & 370500 & 1950 & 296 & 152 & 23 & 159 & & 2.29 & -4.31 & \\
\hline CSW7-31 & Brach frag & $+16.58 \mathrm{~m}$ & $\begin{array}{l}\text { Bird } \\
\text { Spring }\end{array}$ & $\begin{array}{l}\text { Kane Springs } \\
\text { Wash E }\end{array}$ & 385739 & 900 & 736 & 971 & 9 & 67 & 7.44 & 2.74 & -3.29 & \\
\hline CSW7-32 & W & W & W & W & 387151 & 817 & 764 & 794 & 11 & 61 & 5.55 & 2.59 & -3.03 & \\
\hline
\end{tabular}


Appendix A (continued)

\begin{tabular}{|c|c|c|c|c|c|c|c|c|c|c|c|c|c|c|}
\hline Sample \# & Allochem & Horizon & Formation & Location & $\begin{array}{l}\mathrm{Ca} \\
\mathrm{ppm}\end{array}$ & $\begin{array}{l}\mathrm{Mg} \\
\mathrm{ppm}\end{array}$ & $\begin{array}{l}\mathrm{Sr} \\
\mathrm{ppm}\end{array}$ & $\begin{array}{l}\mathrm{Na} \\
\mathrm{ppm}\end{array}$ & $\begin{array}{l}\text { Mn } \\
\text { ppm }\end{array}$ & $\begin{array}{l}\mathrm{Fe} \\
\mathrm{ppm}\end{array}$ & $\mathrm{Fe} / \mathrm{Mn}$ & $\begin{array}{l}\delta^{13} \mathrm{C} \\
\% \circ \\
\end{array}$ & $\begin{array}{l}\delta^{18} \mathrm{O} \\
\% \circ \\
\end{array}$ & ${ }^{87} \mathrm{Sr} /{ }^{86} \mathrm{Sr}$ \\
\hline CSW8-34 & Brach frag & $+15.43 \mathrm{~m}$ & $\begin{array}{l}\text { Bird } \\
\text { Spring }\end{array}$ & $\begin{array}{l}\text { Kane Springs } \\
\text { Wash E }\end{array}$ & 368569 & 2176 & 507 & 1322 & 17 & 94 & 5.53 & 2.82 & -1.88 & \\
\hline CSW8-35 & W & W & W & W & 385269 & 2890 & 594 & 806 & 11 & 62 & 5.64 & 2.68 & -2.28 & \\
\hline CSW8-37 & Matrix & W & W & W & 386016 & 2473 & 373 & 685 & 40 & 258 & & 2.27 & -4.40 & \\
\hline CSW9-38 & Brach frag & $+14.03 \mathrm{~m}$ & $\begin{array}{l}\text { Bird } \\
\text { Spring }\end{array}$ & $\begin{array}{l}\text { Kane Springs } \\
\text { Wash E }\end{array}$ & 383517 & 2217 & 584 & 689 & 14 & 39 & 2.79 & 2.17 & -1.96 & 0.708226 \\
\hline CSW9-39 & W & W & W & W & 383950 & 2568 & 585 & 658 & 20 & 42 & 2.10 & 1.89 & -3.09 & \\
\hline CSW9-41 & Matrix & W & W & W & 361015 & 2721 & 303 & 508 & 40 & 255 & & 2.54 & -4.39 & \\
\hline CSW10-42 & Brach frag & +13.38 m & $\begin{array}{l}\text { Bird } \\
\text { Spring }\end{array}$ & $\begin{array}{l}\text { Kane Springs } \\
\text { Wash E }\end{array}$ & 385312 & 2840 & 596 & 324 & 17 & 58 & 3.41 & 1.84 & -3.19 & \\
\hline CSW10-43 & W & W & W & W & 391415 & 2058 & 588 & 559 & 9 & 59 & 6.56 & 2.41 & -2.74 & \\
\hline CSW10-45 & Matrix & W & W & W & 377935 & 2239 & 336 & 709 & 39 & 113 & & 2.19 & -4.66 & \\
\hline CSW12-46 & Brach frag & +9.38 m & $\begin{array}{l}\text { Bird } \\
\text { Spring }\end{array}$ & $\begin{array}{l}\text { Kane Springs } \\
\text { Wash E }\end{array}$ & 391692 & 2873 & 616 & 731 & 8 & 42 & 5.25 & 2.17 & -1.92 & \\
\hline CSW12-47 & W & W & W & W & 385297 & 1703 & 547 & 617 & 6 & 54 & 9.00 & 2.53 & -1.04 & 0.708208 \\
\hline CSW12-49 & Matrix & W & W & W & 370443 & 1808 & 331 & 621 & 78 & 294 & & 2.29 & -5.04 & \\
\hline CSW13-50 & Brach frag & $+7.08 \mathrm{~m}$ & $\begin{array}{l}\text { Bird } \\
\text { Spring }\end{array}$ & $\begin{array}{l}\text { Kane Springs } \\
\text { Wash E }\end{array}$ & 380621 & 2097 & 526 & 450 & 10 & 86 & 8.60 & 1.63 & -2.31 & \\
\hline CSW13-51 & W & W & W & W & 390742 & 1920 & 546 & 646 & 22 & 96 & 4.36 & 1.50 & -1.91 & \\
\hline CSW13-52 & W & W & W & W & 375300 & 1620 & 542 & 450 & 8 & 26 & 3.25 & 1.24 & -1.50 & 0.708186 \\
\hline CSW13-54 & Matrix & W & W & W & 382723 & 2528 & 313 & 605 & 300 & 229 & & -1.87 & -4.61 & \\
\hline CSW14a-55 & Brach frag & $+0.15 \mathrm{~m}$ & $\begin{array}{l}\text { Bird } \\
\text { Spring }\end{array}$ & $\begin{array}{l}\text { Kane Springs } \\
\text { Wash E }\end{array}$ & 351859 & 761 & 726 & 1096 & 63 & 281 & 4.46 & 1.62 & -3.81 & \\
\hline CSW14a-56 & W & W & W & W & 341760 & 3712 & 378 & & 259 & 794 & & -0.83 & -4.52 & \\
\hline CSW14a-57 & W & W & W & W & 368889 & 444 & 700 & 926 & 38 & 163 & 4.29 & 2.19 & -3.08 & \\
\hline CSW14a-58 & Cement (vein) & W & W & W & 381726 & 1532 & 918 & 461 & 467 & 2833 & & -0.09 & -5.08 & \\
\hline CSW14a-59 & Matrix & W & W & W & 371017 & 2228 & 299 & 416 & 299 & 592 & & -0.81 & -4.32 & \\
\hline CSW14-60 & Spiriferid & $-0.15 \mathrm{~m}$ & $\begin{array}{l}\text { Bird } \\
\text { Spring }\end{array}$ & $\begin{array}{l}\text { Kane Springs } \\
\text { Wash E }\end{array}$ & 344230 & 1253 & 502 & 978 & 63 & 575 & 9.12 & 2.35 & -2.76 & \\
\hline CSW14-61 & W & W & W & W & 371667 & 2600 & 388 & 1696 & 232 & 1788 & & -0.15 & -4.61 & \\
\hline CSW14-62 & W & W & W & W & 376674 & 1783 & 521 & 1544 & 38 & 225 & 5.92 & 2.14 & -2.21 & 0.708221 \\
\hline CSW14-63 & W & W & W & W & 360214 & 1711 & 512 & 2529 & 132 & 1143 & & 1.68 & -3.41 & \\
\hline CSW14-64 & Matrix & W & W & W & 378483 & 2494 & 420 & 658 & 269 & 1697 & & -0.52 & -4.57 & \\
\hline CSW15-65 & Cement & $-0.55 \mathrm{~m}$ & $\begin{array}{l}\text { Bird } \\
\text { Spring }\end{array}$ & $\begin{array}{l}\text { Kane } \\
\text { Springs Wash E }\end{array}$ & 384952 & 2951 & 195 & 51 & 59 & 323 & & -1.43 & -2.91 & \\
\hline CSW15-66 & Brach frag & W & W & W & 391644 & 2684 & 738 & 1044 & 29 & 48 & 1.66 & 3.00 & -1.54 & 0.708178 \\
\hline CSW15-67 & W & W & W & W & 368293 & 2438 & 663 & 1156 & 34 & 89 & 2.62 & 3.35 & -1.79 & \\
\hline CSW15-68 & Matrix & W & W & W & 386283 & 2727 & 411 & 482 & 234 & 1526 & & -0.79 & -4.52 & \\
\hline CSW16-69 & Brach frag & $-1.00 \mathrm{~m}$ & $\begin{array}{l}\text { Bird } \\
\text { Spring }\end{array}$ & $\begin{array}{l}\text { Kane Springs } \\
\text { Wash E }\end{array}$ & 373608 & 2278 & 513 & 1630 & 78 & 329 & 4.22 & 1.11 & -2.94 & \\
\hline CSW16-70 & W & W & W & W & 368351 & 2350 & 473 & 791 & 85 & 170 & 2.00 & 0.75 & -3.18 & \\
\hline CSW16-72 & Matrix & W & W & W & 373769 & 2817 & 409 & 482 & 167 & 510 & & -0.18 & -4.73 & \\
\hline CSW17-73 & Brach frag & $-2.05 \mathrm{~m}$ & $\begin{array}{l}\text { Bird } \\
\text { Spring }\end{array}$ & $\begin{array}{l}\text { Kane Springs } \\
\text { Wash E }\end{array}$ & 397765 & 2085 & 651 & 794 & 30 & 100 & 3.33 & 1.79 & -2.33 & 0.708152 \\
\hline CSW17-74 & W & W & W & W & 393864 & 2892 & 737 & 840 & 17 & 57 & 3.35 & 1.74 & -2.49 & \\
\hline CSW17-76 & Matrix & W & W & W & 359276 & 1975 & 401 & 826 & 134 & 423 & & 0.83 & -3.94 & \\
\hline CSW18-77 & Brach frag & $-2.45 \mathrm{~m}$ & $\begin{array}{l}\text { Bird } \\
\text { Spring }\end{array}$ & $\begin{array}{l}\text { Kane Springs } \\
\text { Wash E }\end{array}$ & 366623 & 656 & 639 & 729 & 21 & 184 & 8.76 & 3.47 & -2.56 & \\
\hline CSW18-78 & W & W & W & W & 368499 & 542 & 639 & 847 & 15 & 142 & 9.47 & 3.63 & -1.63 & \\
\hline CSW18-80 & Matrix & W & W & W & 373500 & 2600 & 497 & 895 & 140 & 656 & & 1.42 & -4.64 & \\
\hline CSW19-81 & Cement & $-4.65 m$ & $\begin{array}{l}\text { Bird } \\
\text { Spring }\end{array}$ & $\begin{array}{l}\text { Kane Springs } \\
\text { Wash E }\end{array}$ & 387896 & 680 & 94 & 32 & 72 & 378 & & 0.94 & -4.95 & \\
\hline CSW19-82 & Matrix & W & W & W & 377323 & 1543 & 220 & 402 & 62 & 302 & & 1.12 & -4.58 & \\
\hline CSW19-83 & Brach frag & W & W & W & 386512 & 1360 & 252 & 698 & 77 & 499 & & 1.11 & -4.54 & \\
\hline CSW19-84 & W & W & W & W & 402378 & 1958 & 311 & 651 & 66 & 243 & & 1.20 & -4.25 & \\
\hline CSW20-85 & Matrix & $-10.5 \mathrm{~m}$ & $\begin{array}{l}\text { Bird } \\
\text { Spring }\end{array}$ & $\begin{array}{l}\text { Kane Springs } \\
\text { Wash E }\end{array}$ & 372188 & 2104 & 284 & 229 & 308 & 412 & & 1.29 & -7.28 & \\
\hline
\end{tabular}


Appendix A (continued)

\begin{tabular}{|c|c|c|c|c|c|c|c|c|c|c|c|c|c|c|}
\hline Sample \# & Allochem & Horizon & Formation & Location & $\begin{array}{l}\text { Ca } \\
\text { ppm }\end{array}$ & $\begin{array}{l}\mathrm{Mg} \\
\mathrm{ppm}\end{array}$ & $\begin{array}{l}\mathrm{Sr} \\
\mathrm{ppm}\end{array}$ & $\begin{array}{l}\mathrm{Na} \\
\mathrm{ppm}\end{array}$ & $\begin{array}{l}\text { Mn } \\
\text { ppm }\end{array}$ & $\begin{array}{l}\text { Fe } \\
\text { ppm }\end{array}$ & $\mathrm{Fe} / \mathrm{Mn}$ & $\begin{array}{l}\delta^{13} \mathrm{C} \\
\% \circ\end{array}$ & $\begin{array}{l}\delta^{18} \mathrm{O} \\
\% \circ\end{array}$ & ${ }^{87} \mathrm{Sr} /{ }^{86} \mathrm{Sr}$ \\
\hline CSW20-86 & Brach frag & W & W & W & 367096 & 794 & 825 & 1420 & 9 & 56 & 6.22 & 2.15 & -4.26 & \\
\hline CSW20-87 & W & W & W & W & 394105 & 926 & 706 & 2047 & 27 & 237 & 8.78 & 3.44 & -2.84 & \\
\hline CSW21-89 & Matrix & $-14.14 m$ & $\begin{array}{l}\text { Bird } \\
\text { Spring }\end{array}$ & $\begin{array}{l}\text { Kane Springs } \\
\text { Wash E }\end{array}$ & 395431 & & 259 & 395 & 288 & 10555 & & -0.07 & -5.92 & \\
\hline CSW21-90 & Brach frag & W & W & W & 378748 & 3118 & 393 & 425 & 54 & 212 & 3.93 & 2.25 & -3.59 & \\
\hline CSW21-91 & W & W & W & W & 377000 & 7258 & 374 & 2857 & 62 & 357 & 5.76 & 2.20 & -3.39 & \\
\hline CSW22-93 & Matrix & $-14.64 m$ & $\begin{array}{l}\text { Bird } \\
\text { Spring }\end{array}$ & $\begin{array}{l}\text { Kane Springs } \\
\text { Wash E }\end{array}$ & 375421 & & 211 & 319 & 259 & 744 & & 0.27 & -7.20 & \\
\hline CSW22-94 & Brach frag & W & W & W & 366728 & 8064 & 381 & 850 & 90 & 330 & & 0.37 & -8.21 & \\
\hline CSW22-95 & W & W & W & W & 372806 & 1425 & 355 & 1158 & 53 & 367 & 6.92 & 2.39 & -3.13 & \\
\hline CSW23-96 & Brach frag & $-16.64 m$ & $\begin{array}{l}\text { Bird } \\
\text { Spring }\end{array}$ & $\begin{array}{l}\text { Kane Springs } \\
\text { Wash E }\end{array}$ & 362650 & 2529 & 318 & 678 & 193 & 292 & & -0.71 & -7.89 & \\
\hline CSW23-97 & W & W & W & W & 362667 & 2373 & 323 & 660 & 197 & 365 & & -0.69 & -7.77 & \\
\hline CSW23-98 & Matrix & W & W & W & 370705 & 3482 & 233 & 399 & 170 & 285 & & -0.55 & -6.86 & \\
\hline CSW23-99 & Cement & W & W & W & 381176 & 635 & 34 & 44 & 339 & 1507 & & -1.62 & -12.09 & \\
\hline AX1-160 & Brach frag & $+0.2 \mathrm{~m}$ & $\begin{array}{l}\text { Bird } \\
\text { Spring }\end{array}$ & Apex & & & & & & & & 0.80 & -2.41 & \\
\hline AX1-161 & Matrix & W & W & W & & & & & & & & -1.90 & -6.16 & \\
\hline AX1-162 & Clast & W & W & W & 385412 & 1976 & 251 & & 56 & 531 & & -5.29 & -3.88 & \\
\hline AX1-163 & Brach frag & W & W & W & 384658 & 767 & 699 & 1449 & 51 & 255 & 5.00 & 2.78 & -2.99 & \\
\hline AX1-164 & W & W & W & W & 360889 & 311 & 646 & 389 & 21 & 599 & & 3.46 & -2.54 & 0.708197 \\
\hline AX2-165 & Brach frag & $-0.5 \mathrm{~m}$ & $\begin{array}{l}\text { Bird } \\
\text { Spring }\end{array}$ & Apex & 391101 & 820 & 585 & 236 & 29 & 248 & 8.85 & 0.44 & -4.15 & \\
\hline AX2-166 & W & W & W & W & 380800 & 567 & 604 & 397 & 33 & 320 & 9.69 & 1.94 & -3.35 & \\
\hline AX2-168 & Matrix & W & W & W & 377538 & 2338 & 343 & 381 & 139 & 679 & & -1.60 & -5.87 & \\
\hline AX2-169 & Cement & W & W & W & 389198 & 2107 & 656 & 67 & 145 & & & -1.39 & -5.19 & \\
\hline AX3-170 & Matrix & $-0.57 \mathrm{~m}$ & $\begin{array}{l}\text { Bird } \\
\text { Spring }\end{array}$ & Apex & 383257 & 3039 & 315 & 376 & 110 & 469 & & -1.27 & -4.67 & \\
\hline AX3-171 & Brach frag & W & W & W & 354538 & 725 & 570 & 529 & 20 & 111 & 5.55 & 0.77 & -3.35 & \\
\hline AX3-172 & W & W & W & W & 382833 & 588 & 789 & 506 & 8 & 27 & 3.38 & 2.62 & -2.27 & 0.708141 \\
\hline AX4-177 & Matrix & $-0.97 \mathrm{~m}$ & $\begin{array}{l}\text { Bird } \\
\text { Spring }\end{array}$ & Apex & 377857 & 2998 & 326 & 146 & 106 & 419 & & -1.10 & -4.50 & \\
\hline AX4-180 & Brach frag & W & W & W & 376713 & 641 & 766 & 737 & 13 & 70 & 5.38 & 2.31 & -2.83 & \\
\hline AX4-181 & W & W & W & W & 349940 & 677 & 583 & 1306 & 26 & 99 & 3.81 & 1.55 & -3.02 & \\
\hline AX5-182 & Matrix & $-1.90 \mathrm{~m}$ & $\begin{array}{l}\text { Bird } \\
\text { Spring }\end{array}$ & Apex & 367513 & 1958 & 259 & 562 & 107 & 612 & & -0.83 & -5.14 & \\
\hline AX5-183 & Brach frag & W & W & W & 381120 & 1920 & 559 & 1380 & 46 & 312 & 6.78 & 1.74 & -3.17 & 0.708181 \\
\hline AX5-185 & W & W & W & W & 371161 & 2460 & 618 & 1402 & 15 & 85 & 5.67 & 2.20 & -2.32 & \\
\hline AX6-187 & Matrix & $-2.10 \mathrm{~m}$ & $\begin{array}{l}\text { Bird } \\
\text { Spring }\end{array}$ & Apex & 370762 & 2489 & 333 & 277 & 86 & 704 & & -0.07 & -4.56 & \\
\hline AX6-188 & Brach frag & W & W & W & 362194 & 2021 & 668 & 725 & 18 & 57 & 3.17 & 1.79 & -3.91 & \\
\hline AX7-191 & Matrix & $-2.8 \mathrm{~m}$ & $\begin{array}{l}\text { Bird } \\
\text { Spring }\end{array}$ & Apex & 376026 & 2434 & 317 & 614 & 94 & 672 & & -0.12 & -4.66 & \\
\hline AX7-194 & Brach frag & W & W & W & 388997 & 3457 & 730 & 778 & 12 & 54 & 4.50 & 1.45 & -3.02 & 0.708139 \\
\hline AX8-195 & Matrix & $-3.5 \mathrm{~m}$ & $\begin{array}{l}\text { Bird } \\
\text { Spring }\end{array}$ & Apex & 375424 & 2979 & 288 & 463 & 59 & 655 & & 0.84 & -5.00 & \\
\hline AX8-196 & Brach frag & W & W & W & 377391 & 3763 & 465 & 1221 & 46 & 516 & & 1.66 & -4.38 & \\
\hline AX9-198 & Matrix & $-3.85 \mathrm{~m}$ & $\begin{array}{l}\text { Bird } \\
\text { Spring }\end{array}$ & Apex & 375535 & 2927 & 321 & 413 & 72 & 626 & & 0.80 & -5.01 & \\
\hline AX9-199 & Cement & W & W & W & 398684 & 3230 & 186 & 177 & 176 & & & 0.63 & -6.57 & \\
\hline AX9-200 & Brach frag & W & W & W & 376800 & 5280 & 468 & 2280 & 96 & 492 & 5.13 & 1.81 & -4.54 & \\
\hline AX10-201 & Matrix & $-8.0 \mathrm{~m}$ & $\begin{array}{l}\text { Bird } \\
\text { Spring }\end{array}$ & Apex & 376579 & 2184 & 338 & 546 & 155 & 810 & & 0.48 & -6.41 & \\
\hline AX10-204 & Spiriferid & W & W & W & 397455 & 836 & 1089 & 1368 & 24 & 120 & 5.00 & 2.95 & -2.42 & \\
\hline AX12-208 & Matrix & $-7.7 \mathrm{~m}$ & $\begin{array}{l}\text { Bird } \\
\text { Spring }\end{array}$ & Apex & 372638 & 2681 & 306 & 413 & 177 & 1029 & & 0.71 & -5.86 & \\
\hline AX12-209 & Spiriferid & W & W & W & 389438 & 770 & 1108 & 1465 & 17 & 41 & 2.41 & $\begin{array}{l}2.91 \\
\text { (continu }\end{array}$ & $\begin{array}{c}-2.34 \\
\text { ued on ne }\end{array}$ & $\begin{array}{l}0.708157 \\
\text { ext page) }\end{array}$ \\
\hline
\end{tabular}


A $9612-210$ W

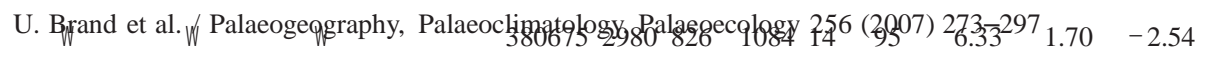


Appendix A (continued)

\begin{tabular}{|c|c|c|c|c|c|c|c|c|c|c|c|c|c|c|}
\hline Sample \# & Allochem & Horizon & Formation & Location & $\begin{array}{l}\mathrm{Ca} \\
\mathrm{ppm}\end{array}$ & $\begin{array}{l}\mathrm{Mg} \\
\mathrm{ppm}\end{array}$ & $\begin{array}{l}\text { Sr } \\
\text { ppm }\end{array}$ & $\begin{array}{l}\mathrm{Na} \\
\mathrm{ppm}\end{array}$ & $\begin{array}{l}\text { Mn } \\
\text { ppm }\end{array}$ & $\begin{array}{l}\text { Fe } \\
\text { ppm }\end{array}$ & $\mathrm{Fe} / \mathrm{Mr}$ & $\begin{array}{l}\delta^{13} \mathrm{C} \\
\% 0\end{array}$ & $\begin{array}{l}\delta^{18} \mathrm{O} \\
\% \circ\end{array}$ & ${ }^{87} \mathrm{Sr} /{ }^{86} \mathrm{Sr}$ \\
\hline AX13-212 & Matrix & $-6.7 \mathrm{~m}$ & $\begin{array}{l}\text { Bird } \\
\text { Spring }\end{array}$ & Apex & 373191 & 2960 & 287 & 379 & 297 & 823 & & 0.45 & -7.14 & \\
\hline AX13-213 & Spiriferid & W & W & W & 388916 & 669 & 970 & 670 & 21 & 54 & 2.57 & 3.16 & -2.67 & \\
\hline AX13-214 & W & W & W & W & 388116 & 678 & 1013 & 892 & 13 & 76 & & 3.24 & -2.60 & \\
\hline AX14-215 & Matrix & $+0.95 \mathrm{~m}$ & $\begin{array}{l}\text { Bird } \\
\text { Spring }\end{array}$ & Apex & 369124 & 3507 & 239 & 396 & 52 & 451 & & 2.23 & -4.01 & \\
\hline AX14-216 & Brach frag & W & W & W & 384000 & 883 & 670 & 186 & 3 & 65 & 7.22 & 3.25 & -2.54 & 0.708226 \\
\hline AX14-217 & W & W & W & W & 379535 & 674 & 691 & 459 & 6 & 46 & 7.67 & 3.01 & -2.32 & \\
\hline AX14-219 & W & W & W & W & 390654 & 426 & 615 & 271 & 1 & 51 & & 3.34 & -2.41 & \\
\hline AX15-220 & Matrix & $+1.45 \mathrm{~m}$ & $\begin{array}{l}\text { Bird } \\
\text { Spring }\end{array}$ & Apex & 390880 & 3618 & 353 & 569 & 57 & 389 & & 2.17 & -5.14 & \\
\hline AX15-221 & Brach frag & W & W & W & 360836 & 1910 & 502 & 715 & 12 & 59 & 4.92 & 2.18 & -4.11 & \\
\hline AX15-222 & W & W & W & W & 371231 & 1654 & 498 & 834 & 7 & 48 & 6.86 & 1.99 & -4.19 & \\
\hline AX16-224 & Matrix & $+1.95 \mathrm{~m}$ & $\begin{array}{l}\text { Bird } \\
\text { Spring }\end{array}$ & Apex & 388005 & 3462 & 244 & 387 & 29 & 373 & & 2.39 & -3.53 & \\
\hline AX16-225 & Brach frag & W & W & W & 378079 & 1040 & 517 & 1031 & 56 & 99 & 1.77 & 3.23 & -2.45 & \\
\hline AX17-227 & Matrix & $+2.2 \mathrm{~m}$ & $\begin{array}{l}\text { Bird } \\
\text { Spring }\end{array}$ & Apex & 380569 & 3440 & 240 & 531 & 22 & 317 & & 2.51 & -4.64 & \\
\hline AX17-229 & Spiriferid & W & W & W & 377190 & 529 & 823 & 485 & 4 & 28 & 7.00 & 4.28 & -1.84 & \\
\hline AX17-230 & W & W & W & W & 376163 & 528 & 795 & 495 & 4 & 26 & 6.50 & 4.33 & -1.87 & 0.708239 \\
\hline AX18-231 & Matrix & $+4.25 \mathrm{~m}$ & $\begin{array}{l}\text { Bird } \\
\text { Spring }\end{array}$ & Apex & 370656 & 2669 & 285 & 496 & 27 & 233 & & 2.01 & -5.22 & \\
\hline AX18-232 & Brach frag & W & W & W & 379949 & 768 & 609 & 843 & 15 & 66 & 4.40 & 3.44 & -3.03 & \\
\hline AX18-233 & W & W & W & W & 379034 & 621 & 625 & 1138 & 14 & 63 & 4.50 & 2.90 & -2.38 & 0.708258 \\
\hline AX19-234 & Matrix & $+5.01 \mathrm{~m}$ & $\begin{array}{l}\text { Bird } \\
\text { Spring }\end{array}$ & Apex & 384472 & 3233 & 312 & 510 & 21 & 211 & & 2.06 & -3.36 & \\
\hline AX19-235 & Brach frag & W & W & W & 381277 & 734 & 742 & 671 & 19 & 60 & 3.16 & 2.63 & -2.71 & \\
\hline AX19-236 & W & W & W & W & 392308 & 923 & 567 & 1096 & 15 & 84 & 5.60 & 2.79 & -1.93 & 0.708241 \\
\hline AX20-237 & Matrix & $+5.45 \mathrm{~m}$ & $\begin{array}{l}\text { Bird } \\
\text { Spring }\end{array}$ & Apex & 379259 & 3062 & 272 & 501 & 42 & 304 & & 1.77 & -3.84 & \\
\hline AX20-238 & Brach frag & W & W & W & 376425 & 3575 & 663 & 1170 & 11 & 64 & 5.82 & 2.11 & -3.38 & \\
\hline AX20-239 & W & W & W & W & & & & & & & & 2.63 & -2.70 & \\
\hline AX21-241 & Matrix & $+6.95 \mathrm{~m}$ & $\begin{array}{l}\text { Bird } \\
\text { Spring }\end{array}$ & Apex & 365083 & 2123 & 346 & 925 & 39 & 310 & & 1.65 & -4.84 & \\
\hline AX21-242 & Brach frag & W & W & W & 380800 & 583 & 726 & 1287 & 34 & 177 & 5.21 & 2.50 & -2.50 & 0.708251 \\
\hline AX21-243 & W & W & W & W & 381707 & 544 & 729 & 952 & 17 & 97 & 5.71 & 2.47 & -2.63 & \\
\hline
\end{tabular}

\section{References}

Adlis, D.S., Grossman, E.L., Yancey, T.E., McLerran, R.D., 1988. Isotope stratigraphy and paleodepth changes of Pennsylvanian cyclical sedimentary deposits. Palaios 3, 487-506.

Auclair, A.-C., Joachimski, M.M., Lécuyer, C., 2003. Deciphering kinetic, metabolic and environmental controls on stable isotope fractionations between seawater and the shell of Terebratalia transversa (Brachiopoda). Chem. Geol. 202, 59-78.

Azmy, K., Veizer, J., Bassett, M.G., Copper, P., Brand, U., 2006. Paleobathymetry of a Silurian shelf based brachiopod assemblage: an oxygen isotope test. Can. J. Earth Sci. 43, 281-293.

Bates, N., Brand, U., 1991. Environmental and physiological influences on isotopic and elemental compositions of brachiopod shell calcite: implications for the isotopic evolution of Paleozoic oceans. Chem. Geol. 94, 67-78.

Bathurst, R.G.C., 1975. Carbonate Sediments and their Diagenesis, 2nd edition. Elsevier. 658 pp.
Bowyer, B., Pampeyan, E.H., Longwell, C.R., 1958. Geologic Map of Clark County, Nevada. United States Geological Survey Mineral Investigations Field Studies Map MF, vol. 138.

Boyd, P., Harrison, P.J., 1999. Phytoplankton dynamics in the NE subarctic Pacific. Deep-Sea Res., Part 2, Top. Stud. Oceanogr. 46, 2405-2432.

Brand, U., 1991. Strontium isotope diagenesis of biogenic aragonite and low-Mg calcite. Geochim. Cosmochim. Acta 55, 505-513.

Brand, U., 2004. Carbon, oxygen and strontium isotopes in Paleozoic carbonate components: an evaluation of original seawaterchemistry proxies. Chem. Geol. 204, 23-44.

Brand, U., Brenckle, P., 2001. Chemostratigraphy of the MidCarboniferous boundary global stratotype section and point (GSSP), Bird Spring Formation, Arrow Canyon, Nevada, USA. Palaeogeogr. Palaeoclimatol. Palaeoecol. 165, 321-347.

Brand, U., Veizer, J., 1980. Chemical diagenesis of a multicomponent carbonate system: 1 . Trace elements. J. Sediment. Petrol. 50, 1219-1236.

Brand, U., Veizer, J., 1981. Chemical diagenesis of a multicomponent carbonate system: 2. Stable isotopes. J. Sediment. Petrol. 51, 987-997. 
Brand, U., Logan, A., Hiller, N., Richardson, J., 2003. Geochemistry of modern brachiopods: applications and implications for oceanography and paleoceanography. Chem. Geol. 198, 305-334.

Brenchley, P.J., Marshall, J.D., Carden, G.A., Robertson, D.B.R, Long, D.G.F., Meidla, T., Hints, L., Anderson, T.F., 1994. Bathymetric and isotopic evidence for a short-lived Late Ordovician glaciation in a greenhouse period. Geology 22, 295-298.

Broecker, W.S., Peng, T.-H., 1982. Tracers in the Sea. Eldigio Press, Palisades, New York. 690 pp.

Bruland, K.W., Lohan, M.C., 2003. Controls of trace metals in seawater. Chapter 6.02. Treatise on Geochemistry. Elsevier Ltd, pp. 23-47.

Bruland, K.W., Rue, E.L., Smith, G.J., 2001. Iron and macronutrients in California coastal upwelling regimes: implications for diatom blooms. Limnol. Oceanogr. 46, 1661-1674.

Bruland, K.W., Rue, E.L., Smith, G.J., DiTullio, G.R., 2005. Iron, macronutrients and diatom blooms in the Peru upwelling regime: brown and blue waters of Peru. Mar. Chem. 93, 81-103.

Buening, N., Spero, H.J., 1996. Oxygen- and carbon-isotope analyses of the articulate brachiopod Laqueus californianus: a recorder of environmental changes in the subeuphotic zone. Mar. Biol. 127, 105-114.

Carpenter, S.J., Lohmann, K.C., 1995. ${ }^{18} \mathrm{O}$ and ${ }^{13} \mathrm{C}$ values of modern brachiopod shells. Geochim. Cosmochim. Acta 59, 3749-3764.

Denison, R.E., Koepnick, R.B., Fletcher, A., Howell, M.W., Callaway, W.S., 1994. Criteria for the retention of original seawater ${ }^{87} \mathrm{Sr} /{ }^{86} \mathrm{Sr}$ in ancient shelf limestones. Chem. Geol. 112, 131-143.

Fasham, M.J.R., Flynn, K.J., Pondaven, P., Anderson, T.R., Boyd, P.W., 2006. Development of a robust marine ecosystem model to predict the role of iron in biogeochemical cycles: a comparison of results fro iron-replete and iron-limited areas, and the SOIREE iron-enrichment experiment. Deep-Sea Res., Part 1, Oceanogr. Res. Pap. 53, 333-366.

Grossman, E.L., 1994. The carbon and oxygen isotope record during the evolution of Pangea: Carboniferous to Triassic. Geol. Soc. Am., Spec. Pap. 288, 207-228.

Heath, C.P., Lumsden, D.N., Carozzi, A.V., 1967. Petrography of a carbonate transgressive-regressive sequence: the Bird Spring Group (Pennsylvanian), Arrow Canyon Range, Clark County, Nevada. J. Sediment. Petrol. 37, 377-400.

Holser, W.T., 1997. Geochemical events documented in inorganic carbon isotopes. Palaeogeogr. Palaeoclimatol. Palaeoecol. 132, 173-182.

Jacobsen, S.B., Kaufman, A.J., 1999. The Sr, C and O isotopic evolution of Neoproterozoic seawater. Chem. Geol. 161, 37-57.

James, N.P., Bone, Y., Kyser, T.K., 1997. Brachiopod $\delta^{18} \mathrm{O}$ values do reflect ambient oceanography: Lacepede Shelf, southern Australia. Geology 25, 551-554.

Joachimski, M.M., van Geldern, R., Breisig, S., Buggisch, W., Day, J., 2004. Oxygen isotope evolution of biogenic calcite and apatite during the Middle and Late Devonian. Int. J. Earth Sci. 93, 542-553.

Johnson, K.S., Gordon, R.M., Coale, K.H., 1997. What controls dissolved iron concentrations in the World Ocean? Mar. Chem. 57, 137-161.

Kroopnick, P., 1985. The distribution of ${ }^{13} \mathrm{C}$ of $\Sigma \mathrm{CO}_{2}$ in the world oceans. Deep-Sea Res. 32, 57-84.

Kump, L.R., Arthur, M.A., 1999. Interpreting carbon-isotope excursions: carbonates and organic matter. Chem. Geol. 161, 181-198.

Lane, H.R., Brenckle, P.L., Baesemann, J.F., Richards, B., 1999. The IUGS boundary in the middle of the Carboniferous: Arrow Canyon, Nevada, USA. Episodes 22, 272-283.

Langenheim Jr., R.L., Langenheim, V.A.M., 1965. The Bird Spring Group, Chesterian through Wolfcampian, at Arrow Canyon, Arrow Canyon Range, Clark County, Nevada. Trans. Ill. State Acad. Sci. 58, 225-240.

Larson, E.R., Langenheim Jr., R.L., 1979. The Mississippian and Pennsylvanian (Carboniferous) Systems in the United States-
Nevada. United States Geological Survey Professional Paper, vol. 1110-BB. 19 pp.

Lécuyer, C., Allemand, P., 1999. Modeling of the oxygen isotope evolution of seawater: implications for the climate interpretation of the $\delta^{18} \mathrm{O}$ of marine sediments. Geochim. Cosmochim. Acta 63, 351-361.

Lee, X., Wan, G., 2000. No vital effect on $\delta^{18} \mathrm{O}$ and $\delta^{13} \mathrm{C}$ values of fossil brachiopod shells, Middle Devonian of China. Geochim. Cosmochim. Acta 64, 2649-2664.

Lee, X., Hu, R., Brand, U., Zhou, H., Liu, X., Yuan, H., Yan, C., Cheng, H., 2004. Ontogenetic trace element distribution in brachiopod shells: an indicator of original seawater chemistry. Chem. Geol. 209, 49-65.

Longwell, C.R., 1960. Possible explanation of diverse structural patterns in southern Nevada. Am. J. Sci., Bradley 258-A, 192-203.

Longwell, C.R., Pampeyan, E.H., Bowyer, B., Roberts, R.J., 1965. Geology and Mineral Deposits of Clark County, Nevada. Nevada Bureau of Mines Bulletin, vol. 62. 218 pp.

Lowenstam, H., 1961. Mineralogy, $\mathrm{O}^{18} / \mathrm{O}^{16}$ ratios, and strontium and magnesium contents of recent and fossil brachiopods and their bearing on the history of the oceans. J. Geol. 69, 241-260.

Mackay, D.J., Parslow, J.S., Griffiths, F.B., Higgins, H.W., Tilbrook, B., 1997. Phytoplankton productivity and the carbon cycle in the western Equatorial Pacific under El Niño and non-El Niño conditions. DeepSea Res., Part 2, Top. Stud. Oceanogr. 44, 1951-1978.

Mackey, D.J., O'Sullivan, J.E., Watson, R.J., 2002. Iron in the western Pacific: riverine or hydrothermal source for iron in the Equatorial Undercurrent? Deep-Sea Res., Part 1, Oceanogr. Res. Pap. 49, 877-893.

Marshall, J.D., 1992. Climatic and oceanographic isotopic signals from the carbonate rock record and their preservation. Geol. Mag. 129, 143-160.

Martin, J.H., Gordon, R.M., Fitzwater, S.E., Broenkow, W.W., 1989. Vertex: phytoplankton/iron studies in the Gulf of Alaska. Deep-Sea Res., Part 1, Oceanogr. Res. Pap. 36, 649-680.

Mii, H.-S., Grossman, E.L., Yancey, T.E., 1999. Carboniferous isotope stratigraphies of North America: implications for Carboniferous paleoceanography and Mississippian glaciation. Geol. Soc. Amer. Bull. 111, 960-973.

Mii, H.-S., Grossman, E.L., Yancey, T.E., Chuvashov, B., Egorov, A., 2001. Isotopic records of brachiopod shells from the Russian Platform - evidence for the onset of mid-Carboniferous glaciation. Chem. Geol. 175, 133-147.

Minas, H.J., Minas, M., 1992. Net community production in 'high nutrient-low chlorophyll" waters of the tropical and Antarctic oceans: grazing vs iron hypothesis. Oceanol. Acta 15, 145-162.

Mohtadi, M., Hebbeln, D., Marchant, M., 2005. Upwelling and productivity along the Peru-Chile Current derived from faunal and isotopic compositions of planktic foraminifer in surface sediments. Mar. Geol. 216, 107-126.

Moore, J.K., Doney, S.C., Glover, D.M., Fung, I.Y., 2002. Iron cycling and nutrient-limitation patterns in surface waters of the World Ocean. Deep-Sea Res., Part 2, Top. Stud. Oceanogr. 49, 463-507.

Morrison, J.O., Brand, U., 1986. Geochemistry of Recent marine invertebrates. Geosci. Can. 13, 237-254.

Pancost, R.D., Freeman, K.H., Wakeman, S.G., Robertson, C.Y., 1997. Controls on carbon isotope fractionation by diatoms in the Peru upwelling region. Geochim. Cosmochim. Acta 61, 4983-4991.

Parkinson, D., Curry, G.B., Cusack, M., Fallick, A.E., 2005. Shell structure, patterns and trends of oxygen and carbon stable isotopes in modern brachiopod shells. Chem. Geol. 219, 193-235.

Popp, B.N., Anderson, T.F., Sandberg, P.A., 1986. Brachiopods as indicators of original isotopic compositions in some Paleozoic limestones. Geol. Soc. Amer. Bull. 97, 1262-1269. 
Price, N.M., Ahner, B.A., Morel, F.M.M., 1994. The equatorial Pacific Ocean: grazer-controlled phytoplankton populations in an ironlimited system. Limnol. Oceanogr. 39, 520-534.

Rau, G.H., Chavez, F.P., Friedrich, G.E., 2001. Plankton ${ }^{13} \mathrm{C} /{ }^{12} \mathrm{C}$ variations in Monterey Bay, California: evidence of non-diffusive inorganic carbon uptake by phytoplankton in an upwelling environment. Deep-Sea Res., Part 1, Oceanogr. Res. Pap. 48, 79-94.

Rich, M., 1977. Pennsylvanian paleogeographic patterns in the western United States. In: Stewart, J.H., Stevens, C.H., Fritsche, A.E. (Eds.), Paleozoic Paleogeography of the Western United States. Pacific Coast Paleogeography Symposium, vol. 1. Pacific Section Society of Economic Paleontologists and Mineralogists, pp. 87-111.

Richards, B.C., Barclay, J.E., Bryan, D., Hartling, A., Henderson, C.M., Hinds, R.C., 1994. Carboniferous strata of the western Canada Sedimentary Basin. In: Mossop, G.D., Shetson, I. (Eds.), Geological Atlas of the Western Canada Sedimentary Basin. Can. Soc. Petrol. Geol., pp. 221-250.

Saltzman, M.R., 2002. Carbon isotope $\left(\delta^{13} C\right)$ stratigraphy across the Silurian-Devonian transition in North America: evidence for a perturbation of the global carbon cycle. Palaeogeogr. Palaeoclimatol. Palaeoecol. 187, 83-100.

Sholkovitz, E.R., Copeland, D., 1983. The coagulation, solubility and adsorption properties of $\mathrm{Fe}, \mathrm{Mn}, \mathrm{Cu}, \mathrm{Ni}, \mathrm{Cd}$, Co and humic acids in river water. Geochim. Cosmochim. Acta 45, 181-189.

Smetacek, V., 1998. Biological oceanography - diatoms and the silicate factor. Nature 391, 224-225.

Sunda, W.G., 1997. Control of dissolved iron concentrations in the world ocean: a comment. Mar. Chem. 57, 169-172.

Sunda, W.G., Swift, D.G., Huntsman, S.A., 1991. Low iron requirement for growth in oceanic phytoplankton. Nature 351, 389-392.

Sverdrup, H.U., Johnson, M.W., Fleming, R.H., 1942. The Oceans, Their Physics, Chemistry, and General Biology. Prince-Hall, Inc., Englewood Cliff, New Jersey. 1062 pp.
Takeda, S., 1998. Influence of iron availability on nutrient consumption ratio of diatoms in oceanic water. Nature 393, 774-777.

Tasch, P., 1980. Paleobiology of the Invertebrates. Wiley and Sons, New York, pp. 251-311.

Thomas, W.H., 1979. Anomalous nutrient-chlorophyll interrelationships in the offshore eastern tropical Pacific Ocean. J. Mar. Res. 37, 327-335.

Thomas, A.C., 1999. Seasonal distribution of satellite-measured phytoplankton pigment concentration along the Chilean coast. J. Geophys. Res. 104, 25877-25890.

Tomascik, T., Mah, A.J., 1997. The ecology of the Indonesian seas. The Ecology of Indonesia Series. Periplus, vol. 7, p. 642.

Veizer, J., Fritz, P., Jones, B., 1986. Geochemistry of brachiopods: oxygen and carbon isotopic records of Paleozoic oceans. Geochim. Cosmochim. Acta 50, 1679-1696.

Veizer, J., Ala, D., Azmy, K., Bruckschen, Buhl, D., Bruhn, F., Carden, G.A.F., Diener, A., Ebneth, S., Godderis, Y., Jasper, T., Korte, C., Pawellek, F., Podlaha, O.G., Strauss, H., $1999 .{ }^{87} \mathrm{Sr} /{ }^{86} \mathrm{Sr}, \delta^{13} \mathrm{C}$ and $\delta^{18} \mathrm{O}$ evolution of Phanerozoic seawater. Chem. Geol. 161, 59-88.

Webster, G.D., 1969. Chester Through Derry Conodont and Stratigraphy of Northern Clark and southern Lincoln Counties, Nevada. University of California Publications in Geological Sciences, vol. 79. 105 pp.

Webster, G.D., Langenheim Jr., R.L., 1979. Stop descriptions seventh day: Clark County, In: Carboniferous stratigraphy in the Grand Canyon country northern Arizona and southern Nevada by Beus, S.S., Rawson, R.R [eds.], Field Trip 12, Ninth Internat. Congress Carb Strat and Geol., Amer Geol. Inst, Guidebook, 73-77.

Zeebe, R.E., 2001. Seawater $\mathrm{pH}$ and isotopic paleotemperatures of Cretaceous oceans. Palaeogeog. Palaeoclimatol. Palaeoecol. 170, 49-57. 